\title{
Transcription factor EB-mediated autophagy promotes dermal fibroblast differentiation and collagen production by regulating endoplasmic reticulum stress and autophagy-dependent secretion
}

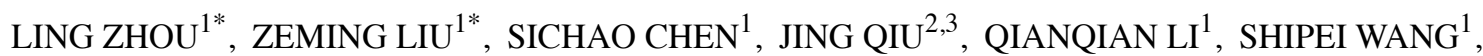 \\ WEI ZHOU $^{1}$, DANYANG CHEN ${ }^{1}$, GUANG YANG ${ }^{2,3}$ and LIANG GUO ${ }^{1}$ \\ ${ }^{1}$ Department of Plastic Surgery, Zhongnan Hospital of Wuhan University, Wuhan, Hubei 430071; \\ ${ }^{2}$ Department of Geriatrics, Hubei Provincial Hospital of Traditional Chinese Medicine; ${ }^{3}$ Department of Geriatrics, \\ Hubei Provincial Academy of Traditional Chinese Medicine, Wuhan, Hubei 430070, P.R. China
}

Received July 14, 2020; Accepted November 11, 2020

DOI: $10.3892 / \mathrm{ijmm} .2020 .4814$

\begin{abstract}
Autophagy is reported to be involved in the formation of skin hypertrophic scar (HTS). However, the role of autophagy in the process of fibrosis remains unclear, therefore an improved understanding of the molecular mechanisms associated with autophagy may accelerate the development of effective therapeutic strategies against HTS. The present study evaluated the roles of autophagy mediated by transcription factor EB (TFEB), a pivotal regulator of lysosome biogenesis and autophagy, in transforming growth factor- $\beta 1$ (TGF- $\beta 1$ )-induced
\end{abstract}

Correspondence to: Dr Liang Guo, Department of Plastic Surgery, Zhongnan Hospital of Wuhan University, 169 Donghu Road, Wuchang, Wuhan, Hubei 430071, P.R. China

E-mail: zhongnanguoliang@163.com

Dr Guang Yang, Department of Geriatrics, Hubei Provincial Hospital of Traditional Chinese Medicine, 320 Zhongshan Road, Wuchang, Wuhan, Hubei 430070, P.R. China

E-mail: hnygzl@126.com

*Contributed equally

Abbreviations: HTS, hypertrophic scar; TGF- $\beta 1$, transforming growth factor- $\beta 1$; TFEB, transcription factor EB; TUDCA, tauroursodeoxycholic acid; GRP78, glucose-regulated proteins 78; p-PERK, phosphorylated-protein kinase R-like endoplasmic reticulum kinase; ATF6, activating transcription factor 6; IRE1 $\alpha$, Inositol-requiring enzyme-1 $\alpha$; LC3, microtubule associated protein 1 light chain 3; LAMP1, lysosome-associated membrane protein 1; CTS B, cathepsin B; p-eIF2 $\alpha$, phosphorylated $\alpha$ subunit of eukaryotic initiation factor 2; CHOP, C/EBP-homologous protein caspase 3; XBP-1s, spliced X-box binding protein 1; caspase 3, cysteinyl aspartate specific proteinase $3 ; \alpha$-SMA, $\alpha$ smooth muscle actin; COL I, collagen I; ER, endoplasmic reticulum; LDH, lactate dehydrogenase; UPR, unfolded protein response

Key words: autophagy, transcription factor EB, hypertrophic scar, endoplasmic reticulum stress, transforming growth factor- $\beta 1$ fibroblast differentiation and collagen production. Fibroblasts were treated with TGF- $\beta 1$, TGF- $\beta 1+$ tauroursodeoxycholic acid (TUDCA) or TGF- $\beta 1$ + TFEB-small interfering RNA (siRNA). TGF- $\beta 1$ induced phenotypic transformation of fibroblasts, as well as collagen synthesis and secretion in fibroblasts in a dose-dependent manner. Western blotting and immunofluorescence analyses demonstrated that TGF- $\beta 1$ upregulated the expression of autophagy-related proteins through the endoplasmic reticulum (ER) stress pathway, whereas TUDCA reversed TGF- $\beta 1$-induced changes. Reverse transcription-quantitative PCR (RT-qPCR), western blotting and RFP-GFP-LC3 double fluorescence analyses demonstrated that knockdown of TFEB by TFEB-siRNA decreased autophagic flux, upregulated the expression of proteins involved in the apoptotic pathway, such as phosphorylated- $\alpha$ subunit of eukaryotic initiation factor 2, C/EBP homologous protein and cysteinyl aspartate specific proteinase 3 , and also downregulated the expression of $\alpha$-smooth muscle actin and collagen I (COL I) in fibroblasts. Immunofluorescence confocal analyses and enzyme-linked immunosorbent assay indicated that TGF- $\beta 1$ increased the colocalization of COL I with lysosomal-associated membrane protein 1 and Ras-related protein Rab-8A, a marker of secretory vesicles, in fibroblasts, as well as the secretion of pro-COL I $\alpha 1$ in culture supernatants. Meanwhile, these effects were abolished by TFEB knockdown. The present results suggested that autophagy reduced ER stress, decreased cell apoptosis and maintained fibroblast activation not only through degradation of misfolded or unfolded proteins, but also through promotion of COL I release from the autolysosome to the extracellular environment.

\section{Introduction}

As a common complication of cutaneous wound healing, hypertrophic scar (HTS) results in unsatisfactory appearance or even permanent loss of normal skin function. Current therapies for HTS include surgical procedures, anti-inflammatory drugs, cytotoxic medications, compression therapy and radiation therapy $(1,2)$. However, these approaches may fail to achieve satisfactory therapeutic effects, and they 
have certain limitations. Although the exact cause for the development of HTS is not yet fully understood, it is typically hypothesized to result from an abnormal response of connective tissues to dermal injury, and is characterized by excessive proliferation of myofibroblasts and aberrant deposition of extracellular matrix (ECM) components, most notably collagen (3). Myofibroblasts are the major source of ECM, including collagen I (COL I), and the key effector cells of HTS. Excessive proliferation of myoblasts is characterized by an increased expression of $\alpha$-smooth muscle actin ( $\alpha$-SMA) $(4,5)$. With the development of HTS, myofibroblasts are continuously hyperactivated and continue to proliferate, leading to excessive synthesis and deposition of collagen (6). Therefore, inhibiting the excessive proliferation and secretion of myofibroblasts may become a potential target for the management of HTS.

Transforming growth factor- $\beta 1$ (TGF- $\beta 1$ ) is considered to be the most potent fibrogenic cytokine in inducing the transformation of fibroblasts into myofibroblasts $(7,8)$. However, given the diversity and complexity of downstream signaling networks regulated by TGF- $\beta 1$, the consequences of complete inhibition of its expression can be difficult to predict. Therefore, targeting the downstream signaling of TGF- $\beta 1$ may be a more practical and promising therapeutic strategy to avoid potential toxicity caused by TGF- $\beta 1$ inhibition. TGF- $\beta 1$ has been reported to regulate the progression and transition of various types of tumors by inducing autophagy $(9,10)$. These findings indicated that autophagy may also serve as a therapeutic target for TGF- $\beta 1$-induced tissue fibrosis. As an evolutionarily conservative process, autophagy facilitates the degradation of damaged organelles or intracellular components, and provides cells with nutrients $(11,12)$. Autophagy is a vital process for the maintenance of cellular homeostasis and cell survival. However, excessive levels of autophagy may result in autophagic cell death. It has been reported that dysregulation of autophagy is closely associated with the pathological process of numerous fibrotic diseases, including liver, kidney and heart disease, as well as cystic fibrosis (13-16). Nevertheless, the roles of autophagy in different fibrotic conditions may be multifaceted and complex. A number of studies have suggested that autophagy is a cytoprotective mechanism (17-19). However, some studies have also indicated that autophagy is involved in promoting fibrosis (20-22). The actual function of autophagy may depend on the specific type and stage of the fibrotic disease. Apart from the aforementioned examples, there is limited information available regarding the role of autophagy in HTS, and the precise molecular mechanisms linking autophagy to HTS need to be further elucidated.

Transcription factor EB (TFEB), a pivotal regulator of lysosome biogenesis and autophagy (23), has become an ideal target for regulating autophagy. In the present study, using TGF- $\beta 1$-treated human skin fibroblasts as a model system, the aim was to investigate whether TFEB mediated-autophagy was involved in fibroblast differentiation and collagen production, and to explore the underlying molecular mechanism in this process, and thus provide a novel perspective for the development of strategies for the treatment of HTS.

\section{Materials and methods}

Cell isolation and culture. The present study was approved by the Medical Ethics Committee of Zhongnan Hospital, Wuhan
University (Wuhan, China; approval no. 2019006). Skin tissues of healthy male patients were collected during circumcision, primary skin fibroblasts were disinfected, cut into small pieces, digested using $0.25 \%$ dispase II (cat. no. 11760200; Roche Diagnostics) at $4^{\circ} \mathrm{C}$ for $24 \mathrm{~h}$, and then digested using $0.2 \%$ collagenase II (cat. no. 17101015; Gibco; Thermo Fisher Scientific, Inc.) at $37^{\circ} \mathrm{C}$ for $4 \mathrm{~h}$. The mixture was vortexed and filtered to obtain a single-cell suspension, which was then added to the culture bottle, and cultured using DMEM (cat. no. 10567014; Gibco; Thermo Fisher Scientific, Inc.) with $10 \%$ calf serum (cat. no. 16010159; Gibco; Thermo Fisher Scientific, Inc.) at $37^{\circ} \mathrm{C}$ in a cell culture incubator with $5 \% \mathrm{CO}_{2}$, culture medium was replaced with fresh medium every 3 days. After reaching $\sim 80 \%$ confluence, cells were digested with $0.25 \%$ trypsin (cat. no. C0201; Beyotime Institute of Biotechnology) and then passaged. Fibroblasts in passages 2-4 were used for further experiments.

Determination of TGF- $\beta 1$ concentration by lactate dehydrogenase $(\mathrm{LDH})$ release assay. $\mathrm{LDH}$ is released upon damage to the plasma membrane of cells, and LDH concentration in the culture medium can be used to evaluate the level of cell damage (24). Fibroblasts of the same passage were seeded onto 24-well plates $\left(5 \times 10^{5}\right.$ cells $\left./ \mathrm{ml}\right)$, and were exposed to TGF- $\beta 1$ (cat. no. AF-100-21C-2; PeproTech, Inc.) at concentrations ranging between 0 and $80 \mathrm{ng} / \mathrm{ml}$ for $48 \mathrm{~h}$. Subsequently, $200 \mu \mathrm{l}$ culture medium was taken from each well and centrifuged at $4^{\circ} \mathrm{C}$ for $5 \mathrm{~min}$ at $300 \mathrm{x} \mathrm{g}$. Next, $20 \mu \mathrm{l}$ of each supernatant sample was added to the corresponding well in a 96-well plate, followed by successive addition of $65 \mu 1$ potassium pyruvate phosphate buffer and $65 \mu \mathrm{l}$ NADH solution. Absorbance measurements were performed using a microplate reader at $340 \mathrm{~nm}$. TGF- $\beta 1$ concentrations were calculated on the basis of the release rates of $\mathrm{LDH}$.

Enzyme-linked immunosorbent assay (ELISA). The secretion levels of pro-COL I $\alpha$ by fibroblasts into the supernatant were detected using an ELISA kit (cat. no.DY6220-05; R\&D Systems, Inc.). Optical density values were measured at $540 \mathrm{~nm}$.

Western blotting. Fibroblasts were seeded into 6-well plates $\left(1 \times 10^{6}\right.$ cells $\left./ \mathrm{ml}\right)$ and treated with TGF- $\beta 1(10 \mathrm{ng} / \mathrm{ml})$ with or without tauroursodeoxycholic acid (TUDCA; $2.5 \mu \mathrm{mol} / \mathrm{l}$; cat. no. T0266; Sigma-Aldrich; Merck KGaA) at $37^{\circ} \mathrm{C}$ for $48 \mathrm{~h}$. Fibroblasts were seeded into 6 -well plates $\left(1 \times 10^{6}\right.$ cells $\left./ \mathrm{ml}\right)$ and transfected with $50 \mathrm{nmol} / 1$ TFEB-siRNA or NC-siRNA for $48 \mathrm{~h}$, and then treated with or without $10 \mathrm{ng} / \mathrm{ml}$ TGF- $\beta 1$ at $37^{\circ} \mathrm{C}$ for $48 \mathrm{~h}$. Cells were collected for lysate preparation. RIPA lysis buffer (cat. no. P0013C; Beyotime Institute of Biotechnology) was used for protein extraction. The protein concentrations of fibroblast lysates were measured using the BCA protein assay kit (cat. no. P0010; Beyotime Institute of Biotechnology). Total protein (20 $\mu \mathrm{g}$ per lane) was loaded onto 10 or $15 \%$ gels and separated via SDS-PAGE, the separated proteins were then transferred onto PVDF membranes (cat. no. IPVH08130; EMD Millipore). Membranes were subsequently blocked with 5\% BSA (cat. no. ST023; Beyotime Institute of Biotechnology) for $1 \mathrm{~h}$ at $25^{\circ} \mathrm{C}$, and incubated with corresponding primary antibodies overnight at $4^{\circ} \mathrm{C}$, including anti-COL I (1:1,000; cat. no. ab6308; Abcam), anti- $\alpha$-SMA 
(1:2,000; cat. no. ab5694; Abcam), anti-glucose-regulated proteins 78 (GRP78; 1:1,000; cat. no. ab32618; Abcam), anti-protein kinase R-like endoplasmic reticulum kinase (PERK; 1:1,000; cat. no. 3192; Cell Signaling Technology, Inc.), anti-phosphorylated (p)-PERK (1:1,000; cat. no. 3179; Cell Signaling Technology, Inc.), anti-activating transcription factor 6 (ATF6; 1:1,000; cat. no. 65880; Cell Signaling Technology, Inc.), anti-inositol-requiring enzyme-1 $\alpha$ (IRE1 $\alpha$; 1:1,000; cat. no. 3294; Cell Signaling Technology, Inc.), anti-lysosome-associated membrane protein 1 (LAMP1; 1:1,000; cat. no. ab62562; Abcam), anti-cathepsin B (CTS B; 1:1,000; cat. no. 31718; Cell Signaling Technology, Inc.), anti-TFEB (1:200; cat. no. ab220695; Abcam), anti- $\alpha$ subunit of eukaryotic initiation factor 2 (eIF2 $\alpha$; 1:1,000; cat. no. 5324; Cell Signaling Technology, Inc.), anti-p-eIF2 $\alpha$ (1:2,000; cat. no. 3398; Cell Signaling Technology, Inc.), anti-spliced X-box binding protein 1 (XBP-1s; 1:2,000; cat. no. 47134; Cell Signaling Technology, Inc.), anti-cysteinyl aspartate specific proteinase 3 (caspase 3; 1:1,000; cat. no. 14220; Cell Signaling Technology, Inc.), anti-microtubule associated protein 1 light chain 3 (LC3; 1:1,000; cat. no. L8918; Sigma-Aldrich; Merck KGaA), anti-p62 (1:1,000; cat. no. SAB1406748; Sigma-Aldrich; Merck KGaA), anti-C/EBP-homologous protein caspase 3 (CHOP; 1:1,000; cat. no. 2895; Cell Signaling Technology, Inc.), anti- $\beta$-actin $(1: 1,000$; cat. no. AF0003; Beyotime Institute of Biotechnology), anti-GAPDH (1:1,000; cat. no. AF1186; Beyotime Institute of Biotechnology) and anti-Histone H3 (1:1,000; cat. no. AF0009; Beyotime Institute of Biotechnology). After washing with TBS with $0.1 \%$ Tween-20, membranes were then incubated with goat anti-rabbit IR dye $800 \mathrm{CW}$ (1:10,000; cat. no. P/N 926-32211; LI-COR Biosciences) or goat anti-mouse $(1: 10,000$; cat. no. P/N 926-32210; LI-COR Biosciences) secondary antibodies at room temperature for $2 \mathrm{~h}$. The intensity of bands was detected using the Odyssey infrared image processing system (LI-COR Biosciences). The gray values of the specific blots were analyzed with Image-Pro Plus version 6.0 software (Media Cybernetics, Inc.).

Reverse transcription-quantitative PCR (RT-qPCR). Total RNA was extracted using TRIzol ${ }^{\circledR}$ reagent (cat. no. 15596026; Invitrogen; Thermo Fisher Scientific, Inc.), and cDNA synthesis was performed using RevertAid First Strand cDNA Synthesis kit (cat. no. K1622; Thermo Fisher Scientific, Inc.), according to the manufacturer's instructions. RT-qPCR was performed using LightCycler ${ }^{\circledR} 96$ System (Roche Diagnostics) and FastStart ${ }^{\mathrm{TM}}$ Universal SYBR Green Master kit (cat. no. 4913850001; Roche Diagnostics). The qPCR thermocycling conditions were as follows: $94^{\circ} \mathrm{C}$ for $3 \mathrm{~min}, 40$ cycles at $95^{\circ} \mathrm{C}$ for $15 \mathrm{sec}, 60^{\circ} \mathrm{C}$ for $30 \mathrm{sec}$ and $72^{\circ} \mathrm{C}$ for $30 \mathrm{sec}$. Relative mRNA levels were normalized to $\beta$-actin and analyzed using the $2^{-\Delta \Delta \mathrm{Cq}}$ method (25). Primer sequences used in this study were as follows: TFEB forward, 5'-ACCTGTCCGAGACCT ATGGG-3' and reverse, 5'-CGTCCAGACGCATAATGTTGT C-3'; and $\beta$-actin forward, 5'-GAAATCGTGCGTGACATT AAAGAG-3' and reverse, 5'-GCGGCAGTGGCCATCTC-3'.

Terminal deoxynucleotidyl transferase-mediated biotinylated UTP nick-end labeling (TUNEL) assay. TUNEL staining was performed to evaluate apoptotic cell death by using the In Situ
Cell Death Detection kit, TMR red (cat. no. 12156792910; Roche Diagnostics), according to the manufacturer's instruction. Cells were fixed on slides using $4 \%$ paraformaldehyde (cat.no.P0098; Beyotime Institute of Biotechnology) for $30 \mathrm{~min}$ and permeabilized with $0.3 \%$ Triton X-100 (cat. no. ST795; Beyotime Institute of Biotechnology) for $10 \mathrm{~min}$ at $25^{\circ} \mathrm{C}$. The slides were washed with PBS, covered with the TUNEL reaction mixture and incubated for $30 \mathrm{~min}$ in the dark. DAPI (cat. no. C1006; Beyotime Institute of Biotechnology) was added for nuclei staining for $15 \mathrm{~min}$ at room temperature. A total of six cell slides per group were examined by fluorescence microscopy (LSM780; Carl Zeiss AG) at x400 magnification, and the proportion of TUNEL-positive stained cells vs. total cells from three random fields of each slice were calculated using Image-Pro Plus 6.0 software (Media Cybernetics, Inc.).

Immunofluorescence staining. Cells were fixed on slides with $2 \%$ paraformaldehyde (cat. no. P0099; Beyotime Institute of Biotechnology) for $15 \mathrm{~min}$ and permeabilized with $0.3 \%$ Triton X-100 for $10 \mathrm{~min}$, and then blocked with 5\% BSA (cat. no. ST023; Beyotime Institute of Biotechnology) for $1 \mathrm{~h}$, all at $25^{\circ} \mathrm{C}$. Subsequently, cells were incubated with the following primary antibodies overnight at $4^{\circ} \mathrm{C}$ : Anti-TFEB (1:50; cat. no. ab220695; Abcam), anti-LAMP1 (1:200; cat. no. ab62562; Abcam), anti-COL I (1:200; cat. no. ab6308; Abcam) and anti-Ras-related protein Rab-8A (Rab8a; 1:200; cat. no. ABIN6290618; Beijing 4A Biotech Co., Ltd.). The slides were then incubated with Alexa Fluor 488-conjugated donkey anti-mouse IgG (1:500; cat. no. A-21202; Invitrogen; Thermo Fisher Scientific, Inc.), Alexa Fluor 555-conjugated donkey anti-rabbit IgG (1:500; cat. no. A-31572; Invitrogen; Thermo Fisher Scientific, Inc.) or Alexa Fluor 647-conjugated donkey anti-goat IgG (1:500; cat. no. A-21447; Invitrogen; Thermo Fisher Scientific, Inc.) at room temperature for $2 \mathrm{~h}$, counterstained with DAPI (cat. no C1006; Beyotime Institute of Biotechnology) for $15 \mathrm{~min}$ at room temperature, and then observed under confocal laser scanning microscope (LSM780; Carl Zeiss AG). Blocking buffer without the primary antibodies was considered the negative control. Image-Pro Plus 6.0 software (Media Cybernetics, Inc.) was used for quantitative analysis of fluorescence microscopy images, and the 'LINE PROFILE' function module was used for line tracing analysis of fluorescence colocalization.

Detection of autophagic flux and small interfering RNA (siRNA)-induced knockdown. Autophagic flux in fibroblasts was detected using Autophagy Tandem Sensor RFP-GFP-LC3B kit (cat. no. P36239; Invitrogen; Thermo Fisher Scientific, Inc.). After TGF- $\beta 1$ treatment for $24 \mathrm{~h}$, fibroblasts were treated with mRFP-GFP-LC3-expressing plasmid for another $24 \mathrm{~h}$. Autophagic flux was quantified by determining the number of autophagosomes (yellow puncta) and autolysosomes (red puncta) per cell per $\mu \mathrm{m}^{2}$.

The following sequences were applied for siRNA-mediated TFEB knockdown: TFEB siRNA-1 sense, 5'-GAAAGG AGACGAAGGUUCAACAUCA-3' and antisense, 5'-AUU CGCUCCUAACCGAGCCAUUCCC-3'; TFEB siRNA-2 sense, 5'-GGAUCAAGGAGCUGGGAAUUU-3' and antisense, 5-AUUCCCAGCUCCUUGAUCCUU-3'. Fibroblasts were seeded into 24 - or 6 -well plates $\left(5.0 \times 10^{5}\right.$ cells $/ \mathrm{ml}$ or 
$1.0 \times 10^{6}$ cells $/ \mathrm{ml}$ ) and transfected with $50 \mathrm{nmol} / 1$ TFEB-siRNA for $48 \mathrm{~h}$ at $37^{\circ} \mathrm{C}$ using Lipofectamine ${ }^{\circledR}$ RNAiMAX transfection reagent (cat. no. 13778075; Invitrogen; Thermo Fisher Scientific, Inc.). Negative control (NC)-siRNA was used as the control (sense, 5'-UAGCGACUAAACACAUCAAUU-3' and antisense, 5'-UUGAUGUGUUUAGUCGCUAUU-3'). After transfection with TFEB-siRNA or NC-siRNA for $48 \mathrm{~h}$, the cells were then treated with $10 \mathrm{ng} / \mathrm{ml} \mathrm{TGF}-\beta 1$ for $48 \mathrm{~h}$ at $37^{\circ} \mathrm{C}$. TFEB-siRNA and siRNA NC were purchased from BrainVTA (Wuhan) Co., Ltd.

Statistical analysis. GraphPad Prism 6.0 software (GraphPad Software, Inc.) was used for statistical analyses. Data are expressed as the mean \pm standard deviation and were analyzed using one-way analysis of variance followed by Tukey's post hoc test. Pearson's correlation analysis was used to determine the correlation between protein colocalization. $\mathrm{P}<0.05$ was considered to indicate a statistically significant difference.

\section{Results}

TGF- $\beta 1$ promotes fibroblastic phenotypic transformation as well as collagen synthesis and secretion in fibroblasts in a dose-dependent manner. In the present study, TGF- $\beta 1$-treated human dermal fibroblasts were used as a model of HTS pathogenesis. To determine the optimal concentrations of TGF- $\beta 1$ for fibroblast treatment, the effects of different concentrations of TGF- $\beta 1$ on the integrity and viability of fibroblasts were investigated. Cells were treated with $0,2.5,5,10,20,40$ or $80 \mathrm{ng} / \mathrm{ml}$ TGF- $\beta 1$ for $48 \mathrm{~h}$, and the concentrations of LDH released from fibroblasts were determined. Treatment with $80 \mathrm{ng} / \mathrm{ml}$ TGF- $\beta 1$ induced a significant increase in LDH release from fibroblasts, whereas treatment with $40 \mathrm{ng} / \mathrm{ml}$ TGF- $\beta 1$ produced a small and insignificant increase in $\mathrm{LDH}$ release compared with the control (Fig. 1A). Hence, 2.5-20 ng/ml TGF- $\beta 1$ was selected for further evaluation.

The effects of different concentrations of TGF- $\beta 1$ on COL I and $\alpha$-SMA expression levels in the fibroblasts were detected by western blotting. Basal expression levels of COL I and $\alpha$-SMA in fibroblasts were low, but following treatment with TGF- $\beta 1$, COL I (Fig. 1C) and $\alpha$-SMA (Fig. 1D) expression significantly increased in a dose-dependent manner in cells, which started to occur at the concentration of $5 \mathrm{ng} / \mathrm{ml}$ and reached a maximum at $20 \mathrm{ng} / \mathrm{ml}$. Similar trends were also observed in the secretion levels of pro-COL I $\alpha 1$ (Fig. 1B) in the supernatant. However, there was no difference in COL I expression or pro-COL I $\alpha 1$ secretion in fibroblasts treated with 10 and $20 \mathrm{ng} / \mathrm{ml}$ TGF- $\beta 1$. Therefore, $10 \mathrm{ng} / \mathrm{ml}$ was used as the optimal concentration in subsequent experiments.

TGF- $\beta 1$ triggers autophagy upregulation through endoplasmic reticulum (ER) stress in fibroblasts. Whether and how TGF- $\beta 1$ induced autophagy in primary human dermal fibroblasts was next evaluated. Western blotting analysis showed that treatment with $10 \mathrm{ng} / \mathrm{ml}$ TGF- $\beta 1$ led to increased expression of ER stress-related proteins in fibroblasts compared with the control group, including GRP78 (1.73 \pm 0.30 vs. $1.00 \pm 0.24$; $\mathrm{P}<0.01$; Fig. $2 \mathrm{~A})$, p-PERK $(2.13 \pm 0.19$ vs. $1.00 \pm 0.12 ; \mathrm{P}<0.01$;

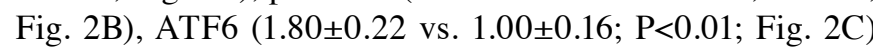
and IRE1 $\alpha(2.38 \pm 0.26$ vs. $1.00 \pm 0.18 ; \mathrm{P}<0.01$; Fig. $2 \mathrm{D})$. As shown in Fig. 2E-H, TGF- $\beta 1(10 \mathrm{ng} / \mathrm{ml})$ triggered autophagy upregulation in fibroblasts compared with the control group, as evidenced by higher expression levels of LC3 II (3.24 \pm 0.31 vs. $1.00 \pm 0.15 ; \mathrm{P}<0.01$; Fig. $2 \mathrm{E})$, LAMP1 (2.26 \pm 0.19 vs. $1.00 \pm 0.24$; $\mathrm{P}<0.01$; Fig. $2 \mathrm{G})$ and CTS B (1.98 \pm 0.12 vs. $1.00 \pm 0.24 ; \mathrm{P}<0.01$; Fig. $2 \mathrm{H})$, along with reduced expression of p62 (0.31 \pm 0.09 vs. $1.00 \pm 0.15 ; \mathrm{P}<0.01$; Fig. 2F). Notably, TUDCA, an inhibitor of ER stress, significantly reversed the upregulation of autophagy $(\mathrm{P}<0.05$ or $\mathrm{P}<0.01$; Fig. $2 \mathrm{~A}-\mathrm{H})$, indicating that ER stress is essential for TGF- $\beta 1$-induced autophagy.

The present study also evaluated the effect of TGF- $\beta 1$ on the activation/overexpression of TFEB, which is a central regulator of lysosomal biogenesis and autophagy (23). TFEB activation/overexpression has been shown to promote the degradation of autophagy substrates (23). Western blotting assays were performed to determine the distributions in the nuclear $(2.15 \pm 0.30$ vs. $1.00 \pm 0.14 ; \mathrm{P}<0.01$; Fig. $3 \mathrm{~A})$ and cytoplasmic $(2.23 \pm 0.22$ vs. $1.00 \pm 0.26 ; \mathrm{P}<0.01$; Fig. $3 \mathrm{~B})$ fractions of TFEB, showing that TGF- $\beta 1$ treatment resulted in increased protein expression and nuclear translocation of TFEB in fibroblasts compared with the control group. TGF- $\beta 1$ also increased the fluorescence intensity of TFEB compared with the control group in the nucleus $(3.47 \pm 0.43$ vs. $1.00 \pm 0.24 ; \mathrm{P}<0.01$; Fig. $3 \mathrm{C})$ and the cytoplasm $(1.93 \pm 0.20$ vs. $1.00 \pm 0.11 ; \mathrm{P}<0.01$; Fig. $3 \mathrm{C})$. TUDCA also reduced the activity of TGF- $\beta 1$-induced TFEB transcription $(\mathrm{P}<0.01$; Fig. 3A-C).

Knockdown of TFEB enhances TGF- $\beta 1$-induced ER stress and apoptosis, while it reduces fibroblastic phenotypic transformation and collagen synthesis in fibroblasts. To further understand whether autophagy plays a significant role in ER stress, fibroblastic phenotypic transformation, as well as collagen synthesis and secretion in fibroblasts, gene knockdown of TFEB was performed using siRNA. Compared with the control group, efficient knockdown of TFEB was confirmed by RT-qPCR $(0.31 \pm 0.17$ vs. $1.00 \pm 0.36 ; \mathrm{P}<0.05$; Fig. $4 \mathrm{~A})$ and western blotting $(0.46 \pm 0.21$ vs. $1.00 \pm 0.30 ; \mathrm{P}<0.05$; Fig. $4 \mathrm{~B}$; $1.47 \pm 0.34$ vs. $2.50 \pm 0.44 ; \mathrm{P}<0.01$; Fig. S1A). Knockdown of TFEB significantly reversed the increased expression of LC3 (1.43 \pm 0.16 vs. $2.80 \pm 0.21 ; \mathrm{P}<0.01$; Fig. 4C; $1.47 \pm 0.27$ vs. $3.02 \pm 0.37$; $<<0.01$; Fig. S1B) and LAMP1 (1.34 \pm 0.18 vs. $2.22 \pm 0.18 ; \mathrm{P}<0.01$; Fig. $4 \mathrm{D} ; 1.47 \pm 0.25$ vs. $2.24 \pm 0.34 ; \mathrm{P}<0.01$; Fig. S1C) induced by TGF- $\beta 1$.

For an improved quantitative assessment of autophagy, $50 \mathrm{nmol} / 1$ TFEB-siRNA or NC-siRNA was used to block the fusion of lysosomes and autophagosomes, and autophagic flux was assessed using an RFP-GFP-LC3 plasmid, in which yellow puncta reflect combined GFP and RFP fluorescence, representing autophagosomes, while red puncta (RFP only) represent autolysosomes. The accumulation of both yellow puncta $(0.157 \pm 0.025$ vs. $0.037 \pm 0.006 ; \mathrm{P}<0.01$; Fig. $5 \mathrm{~A}$ and $\mathrm{B})$ and red puncta $(0.064 \pm 0.018$ vs. $0.017 \pm 0.003 ; \mathrm{P}<0.01$; Fig. 5A and B) were significantly increased by TGF- $\beta 1$ treatment compared with the control. Compared with the TGF- $\beta 1$ treatment group, transfection with TFEB-siRNA significantly decreased the amount of yellow puncta $(0.056 \pm 0.009$ vs. $0.157 \pm 0.025 ; \mathrm{P}<0.01$; Fig. $5 \mathrm{~A}$ and $\mathrm{B})$ and red puncta $(0.029 \pm 0.008$ vs. $0.064 \pm 0.018 ; \mathrm{P}<0.01$; Fig. $5 \mathrm{~A}$ and $\mathrm{B})$; however, no significant difference was detected between the TGF- $\beta 1$ group and TGF- $\beta 1+$ NC-siRNA group. 
A

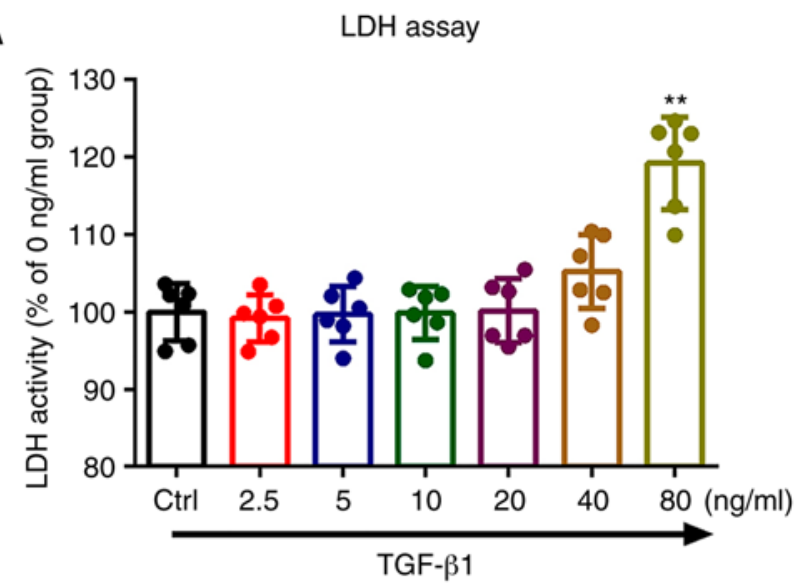

C

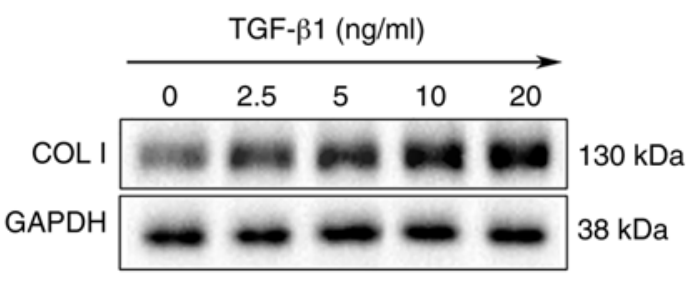

COLI

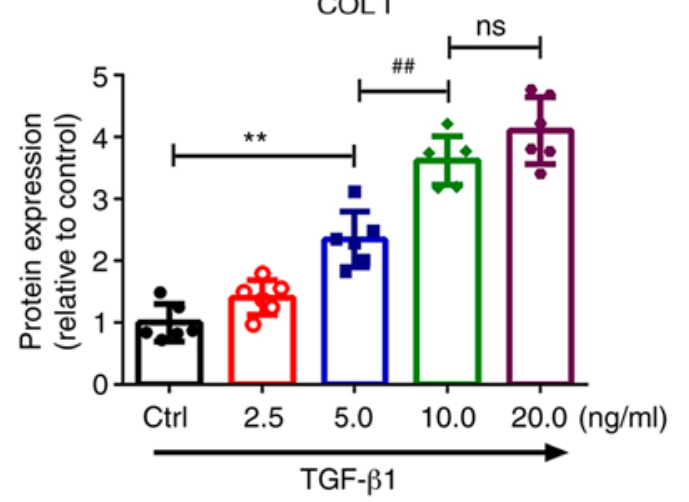

B Pro-COL l $\alpha 1$ of cell supernatant
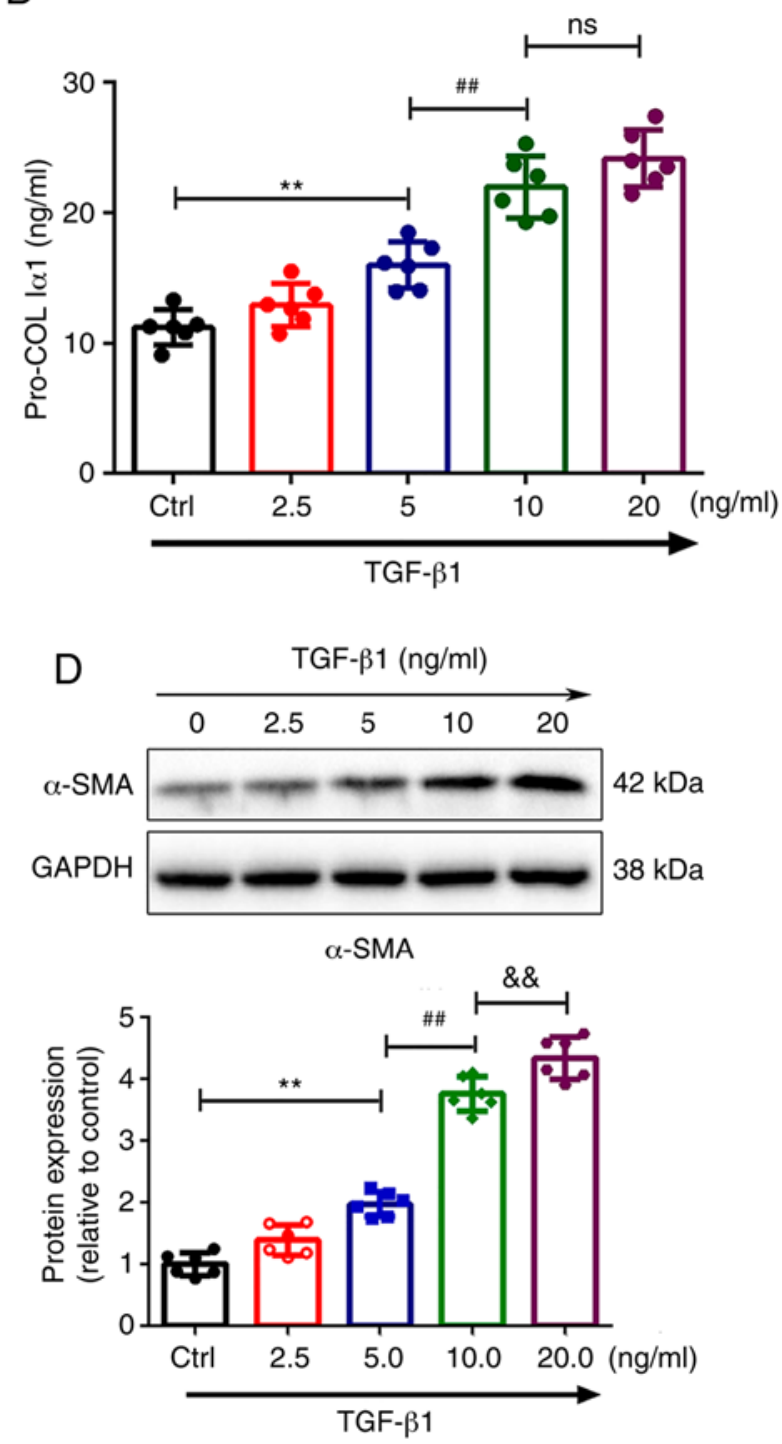

Figure 1. TGF- $\beta 1$ promotes phenotypic transformation of fibroblasts, and collagen synthesis and secretion in fibroblasts. (A) Fibroblasts were treated with $0,2.5,5,10,20,40$ or $80 \mathrm{ng} / \mathrm{ml}$ TGF- $\beta 1$ for $48 \mathrm{~h}$ and LDH release was then determined. (B) Secretion of pro-COL I $\alpha 1$ in fibroblasts was assessed by ELISA. Expression of (C) COL I and (D) $\alpha$-SMA in fibroblasts was measured by western blotting after treatment with $0,2.5,5,10 \mathrm{or} 20 \mathrm{ng} / \mathrm{ml}$ TGF- $\beta 1 \mathrm{for} 48 \mathrm{~h}$. GAPDH served as a loading control. Results are presented as the mean $\pm \mathrm{SD}(\mathrm{n}=6) .{ }^{* *} \mathrm{P}<0.01$ vs. control group; ${ }^{\# \#} \mathrm{P}<0.01$ vs. $5 \mathrm{ng} / \mathrm{ml}$ TGF- $\beta 1$ treatment group; ${ }^{\& \&} \mathrm{P}<0.01$ vs. $10 \mathrm{ng} / \mathrm{ml}$ TGF- $\beta 1$ treatment group. TGF- $\beta 1$, transforming growth factor- $\beta 1$; LDH, lactate dehydrogenase; ELISA, enzyme-linked immunosorbent assay; COL I, collagen I; $\alpha$-SMA, $\alpha$-smooth muscle actin; ns, not significant.

Compared with the fibroblasts treated with TGF- $\beta 1$, transfection with TFEB-siRNA significantly increased the expression of p-eIF2 $\alpha$ ( $3.78 \pm 0.54$ vs. $2.75 \pm 0.35$; P $<0.01$; Fig. 6 A; $3.51 \pm 0.46$ vs. $2.80 \pm 0.37 ; \mathrm{P}<0.05 ;$ Fig. S2A), XBP-1s (3.20 \pm 0.34 vs.1.93 \pm 0.18 ; $\mathrm{P}<0.01$; Fig. $6 \mathrm{~B} ; 3.13 \pm 0.41$ vs. $1.97 \pm 0.38$; $\mathrm{P}<0.01$; Fig. S2B) and CHOP $(2.29 \pm 0.41$ vs. $1.88 \pm 0.20$; P $<0.05$; Fig. 6 C ; $2.56 \pm 0.42$ vs. $1.81 \pm 0.30 ; \mathrm{P}<0.01$; Fig. S2C), which are associated with a predisposition to cell death (26), and also increased the levels of cleaved caspase 3 , a marker of apoptosis ( $2.43 \pm 0.30$ vs. $1.07 \pm 0.18$; $\mathrm{P}<0.01$; Fig. $6 \mathrm{E} ; 2.18 \pm 0.19$ vs. $1.12 \pm 0.20 ; \mathrm{P}<0.01$; Fig. $\mathrm{S} 3 \mathrm{~A})$ compared with the TGF- $\beta 1$ treatment group. TUNEL staining also demonstrated that knockdown of TFEB induced apoptotic cell death $(32.95 \pm 4.11$ vs. $7.59 \pm 0.80 ; \mathrm{P}<0.01$; Fig. $6 \mathrm{D})$ compared with the TGF- $\beta 1$ treatment group. However, TFEB-siRNA did not induce apoptosis in quiescent fibroblasts without TGF- $\beta 1$ treatment (Fig. 6D and E).
The results also demonstrated that the knockdown of TFEB significantly reduced the expression levels of COL I $(1.87 \pm 0.31$ vs. $3.48 \pm 0.40$; $\mathrm{P}<0.01$; Fig. $6 \mathrm{~F} ; 2.07 \pm 0.34$ vs. $3.39 \pm 0.41 ; \mathrm{P}<0.01$; Fig. S3B $)$ and $\alpha$-SMA $(2.13 \pm 0.29$ vs. $3.77 \pm 0.37$; $\mathrm{P}<0.01$; Fig. $6 \mathrm{G} ; 2.24 \pm 0.42$ vs. $3.99 \pm 0.36$; $\mathrm{P}<0.01$; Fig. $\mathrm{S3C}$ ) compared with the TGF- $\beta 1$ treatment group.

TGF- $\beta 1$-induced COL I secretion is associated with an autophagy-based unconventional secretory pathway and is mediated by Rab8a activity. Since fibroblasts do not contain any evidently large coat protein complex II (COPII) structures, and collagens are too large to be incorporated into conventional 80-nm COPII-coated vesicles (27), the present study further explored whether autophagy is an alternative secretory pathway of collagen trafficking. Fibroblasts were transfected with $50 \mathrm{nmol} / \mathrm{l}$ TFEB-siRNA or NC-siRNA, and 

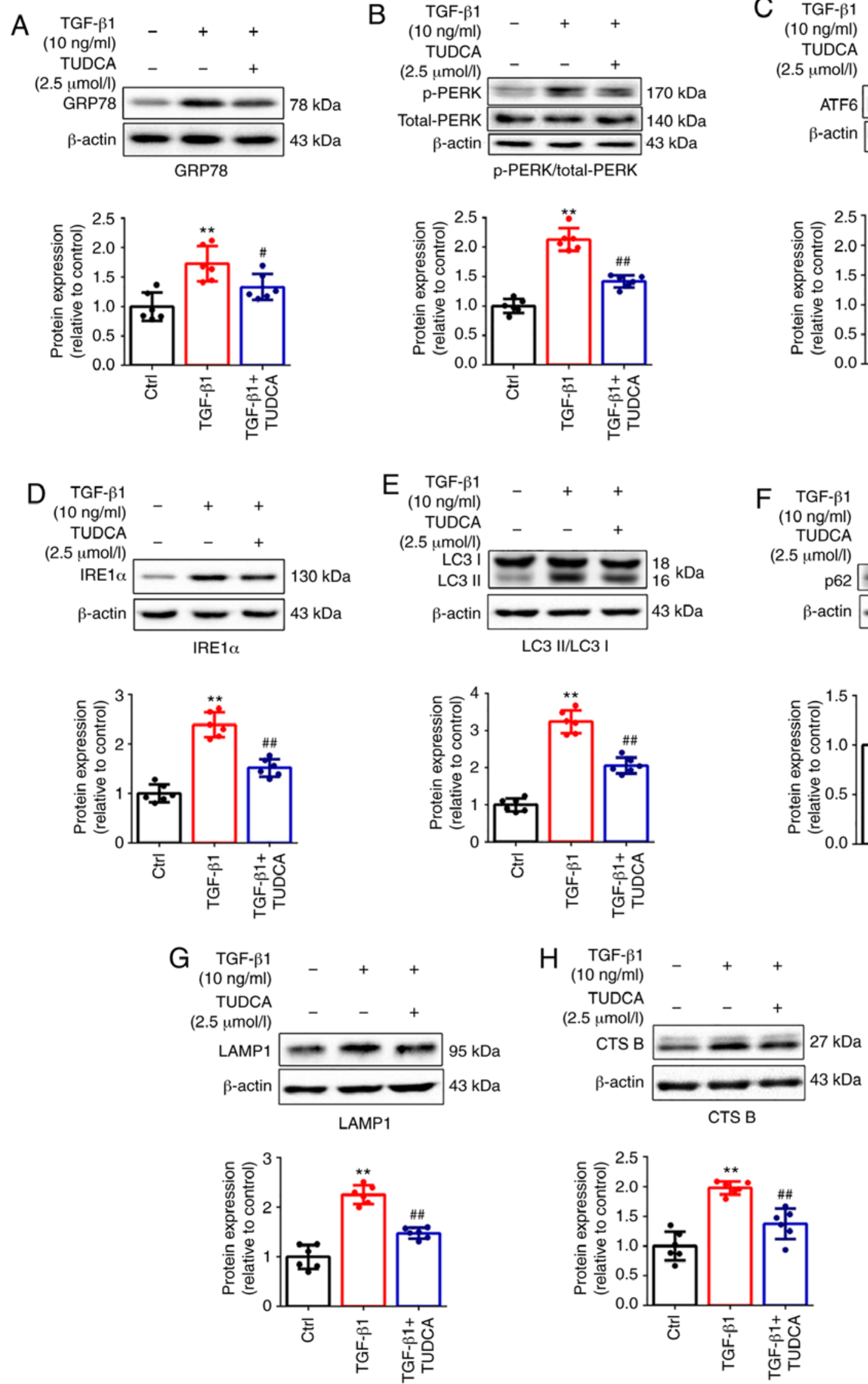
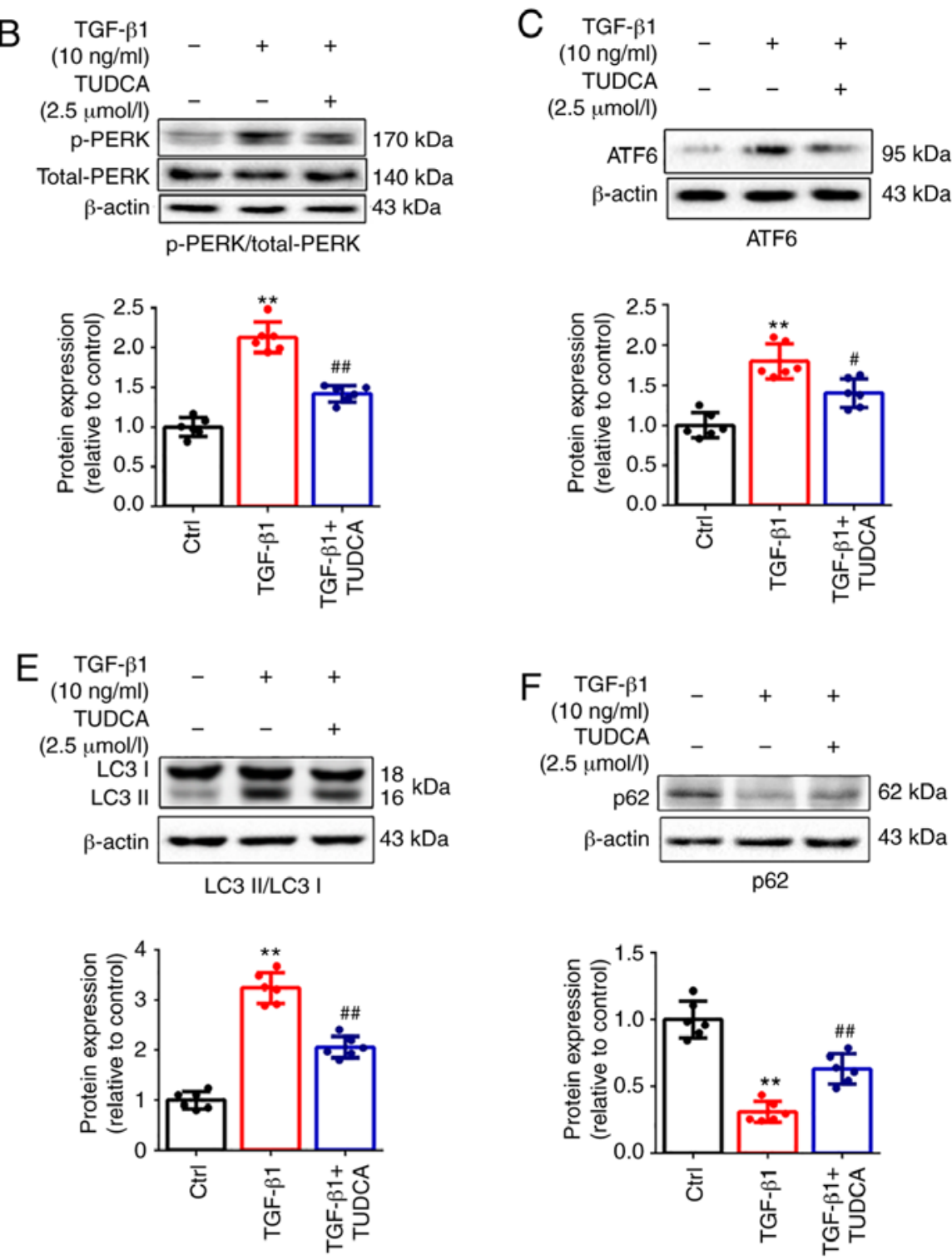

Figure 2 . ER stress caused by TGF- $\beta 1$ triggers autophagy, which is repressed by TUDCA in fibroblasts. Fibroblasts were treated with TGF- $\beta 1$ (10 ng/ml) for $48 \mathrm{~h}$ with or without TUDCA $(2.5 \mu \mathrm{mol} / 1)$. Representative immunoblots of cultured fibroblasts, with detection of (A) GRP78, (B) p-PERK/total-PERK, (C) ATF6, (D) IRE1 $\alpha$, (E) LC3 II/I, (F) p62, (G) LAMP1 and (H) CTS B. Results are presented as the mean \pm SD (n=6). ${ }^{* *} \mathrm{P}<0.01$ vs. control group; ${ }^{\#} \mathrm{P}<0.05$ and ${ }^{\#} \mathrm{P}<0.01$ vs. TGF- $\beta 1$ treatment group. ER, endoplasmic reticulum; TGF- $\beta 1$, transforming growth factor- $\beta 1$; TUDCA, tauroursodeoxycholic acid; GRP78, glucose-regulated proteins 78; p-, phosphorylated; PERK, protein kinase R-like endoplasmic reticulum kinase; ARF6, activating transcription factor 6; IRE1 $\alpha$, inositol-requiring enzyme-1 $\alpha$; LC3, microtubule associated protein 1 light chain 3; LAMP1, lysosome-associated membrane protein 1; CTS B, cathepsin B. 

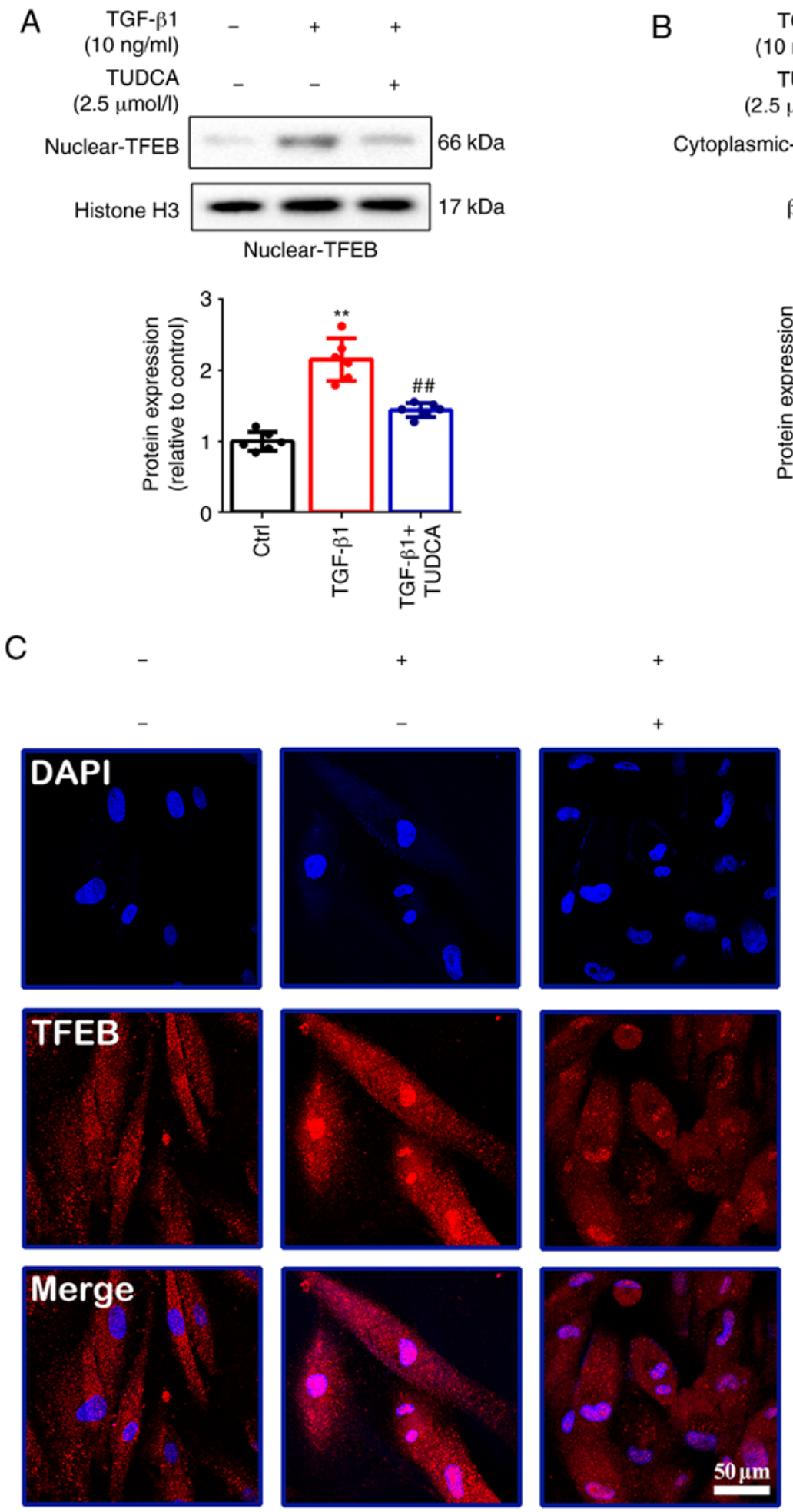

B
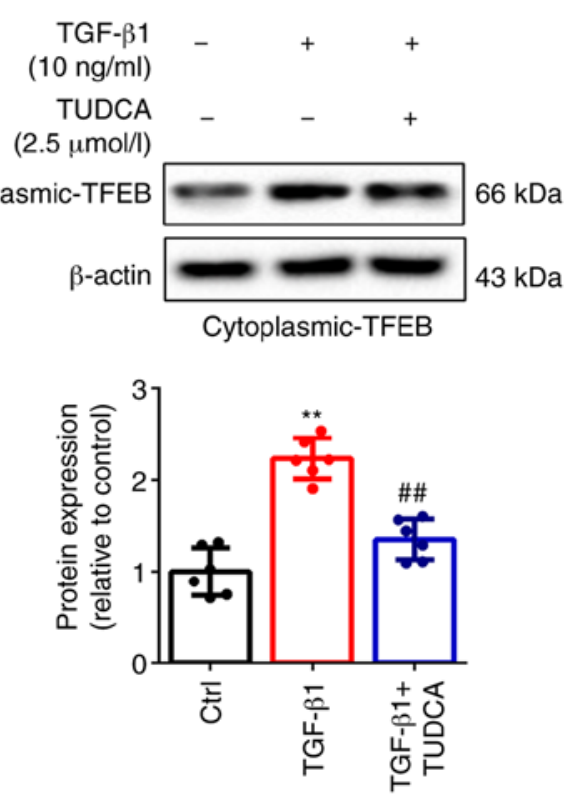

TGF- $\beta 1$

$(10 \mathrm{ng} / \mathrm{ml})$

TUDCA

$(2.5 \mu \mathrm{mol} / \mathrm{l})$
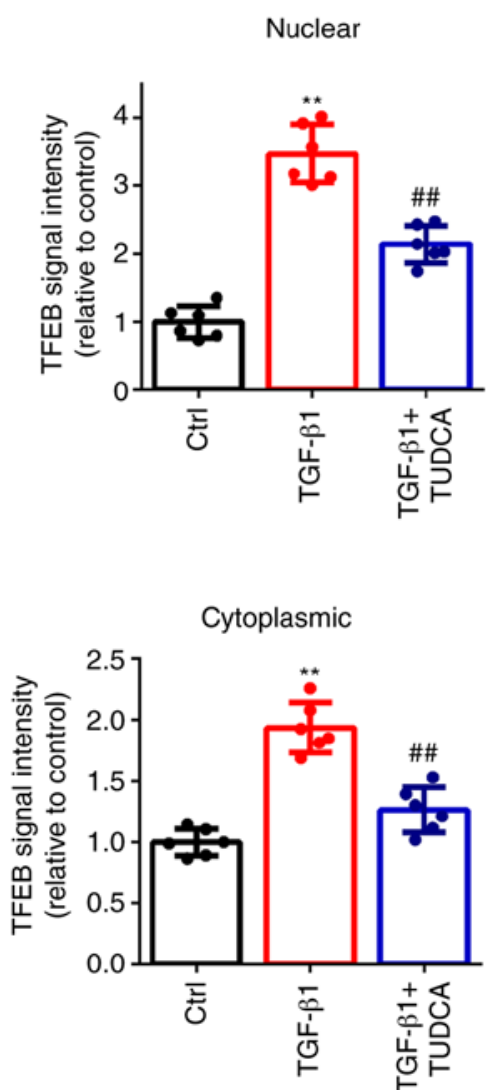

Figure 3. TGF- $\beta 1$ increases TFEB transcriptional activity. Fibroblasts were treated with TGF- $\beta 1(10 \mathrm{ng} / \mathrm{ml})$ for $48 \mathrm{~h}$ with or without TUDCA (2.5 $\mu$ mol/l). The expression of TFEB in the (A) nucleus and (B) cytoplasm was measured using western blotting. Histone $\mathrm{H} 3$ or $\beta$-actin served as a loading control. (C) Immunofluorescent imaging of TFEB (red) and DAPI (blue) in fibroblasts showed an enrichment of the TFEB signal in the nucleus (scale bar, $50 \mu \mathrm{m}$ ). The fluorescence intensity of TFEB in nucleus and cytoplasm was calculated and statistically analyzed. Results are presented as the mean $\pm \mathrm{SD}(\mathrm{n}=6)$. ${ }^{* *} \mathrm{P}<0.01 \mathrm{vs}$. control group; ${ }^{\# \#} \mathrm{P}<0.01$ vs. TGF- $\beta 1$ treatment group. TGF- $\beta 1$, transforming growth factor- $\beta 1$; TUDCA, tauroursodeoxycholic acid.

then treated with TGF- $\beta 1(10 \mathrm{ng} / \mathrm{ml})$. Immunofluorescence analysis showed that TGF- $\beta 1$ increased the colocalization of COL I with the lysosome marker LAMP1 $(0.59 \pm 0.12$ vs.
$0.18 \pm 0.05 ; \mathrm{P}<0.01$; Fig. 7A-C) and Rab8a (0.54 \pm 0.08 vs. $0.13 \pm 0.04$; $\mathrm{P}<0.01$; Fig. $7 \mathrm{~A}, \mathrm{~B}$ and $\mathrm{D})$, a marker of secretory autophagy vesicles, and also upregulated the secretion 
A

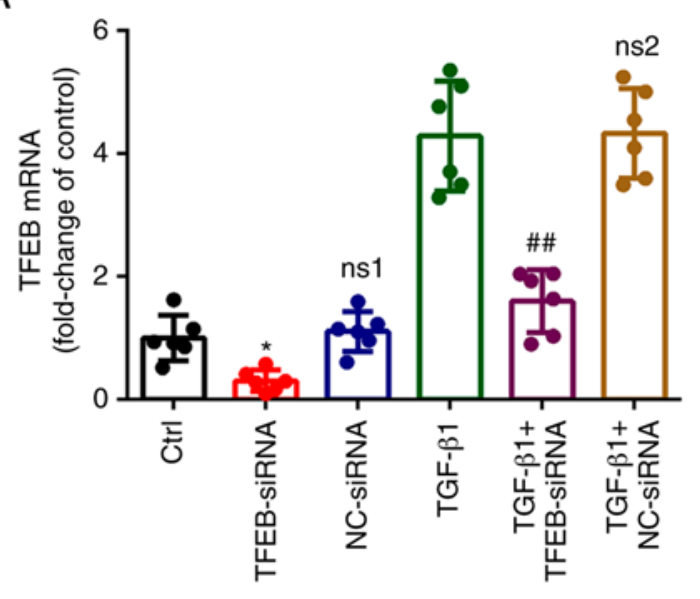

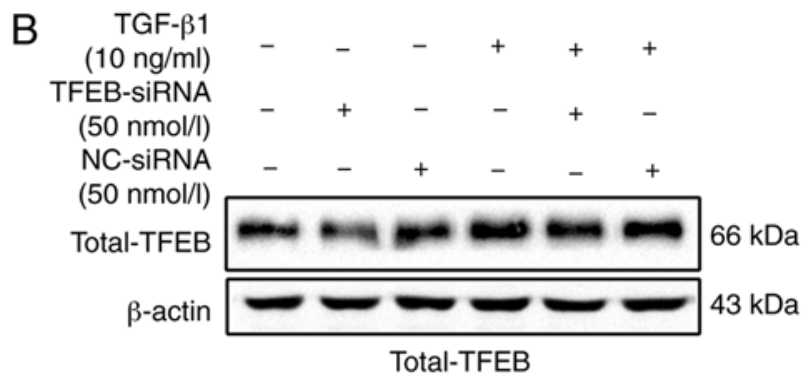

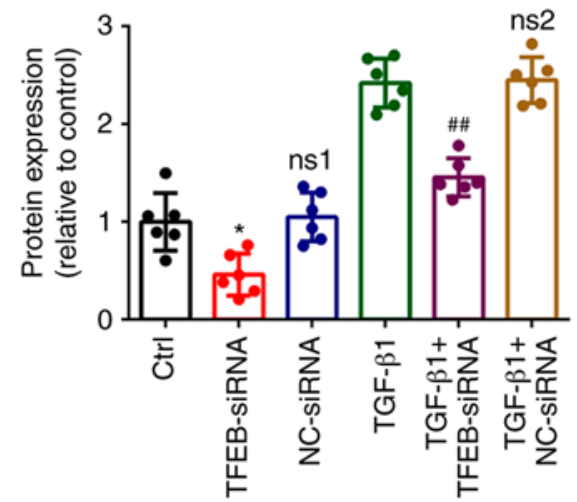

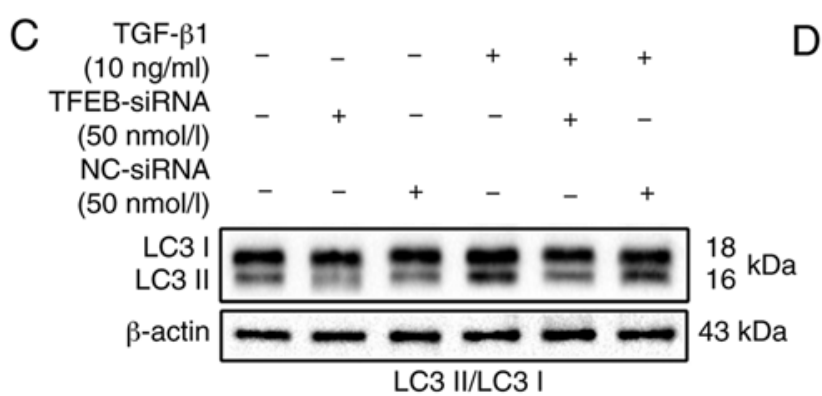
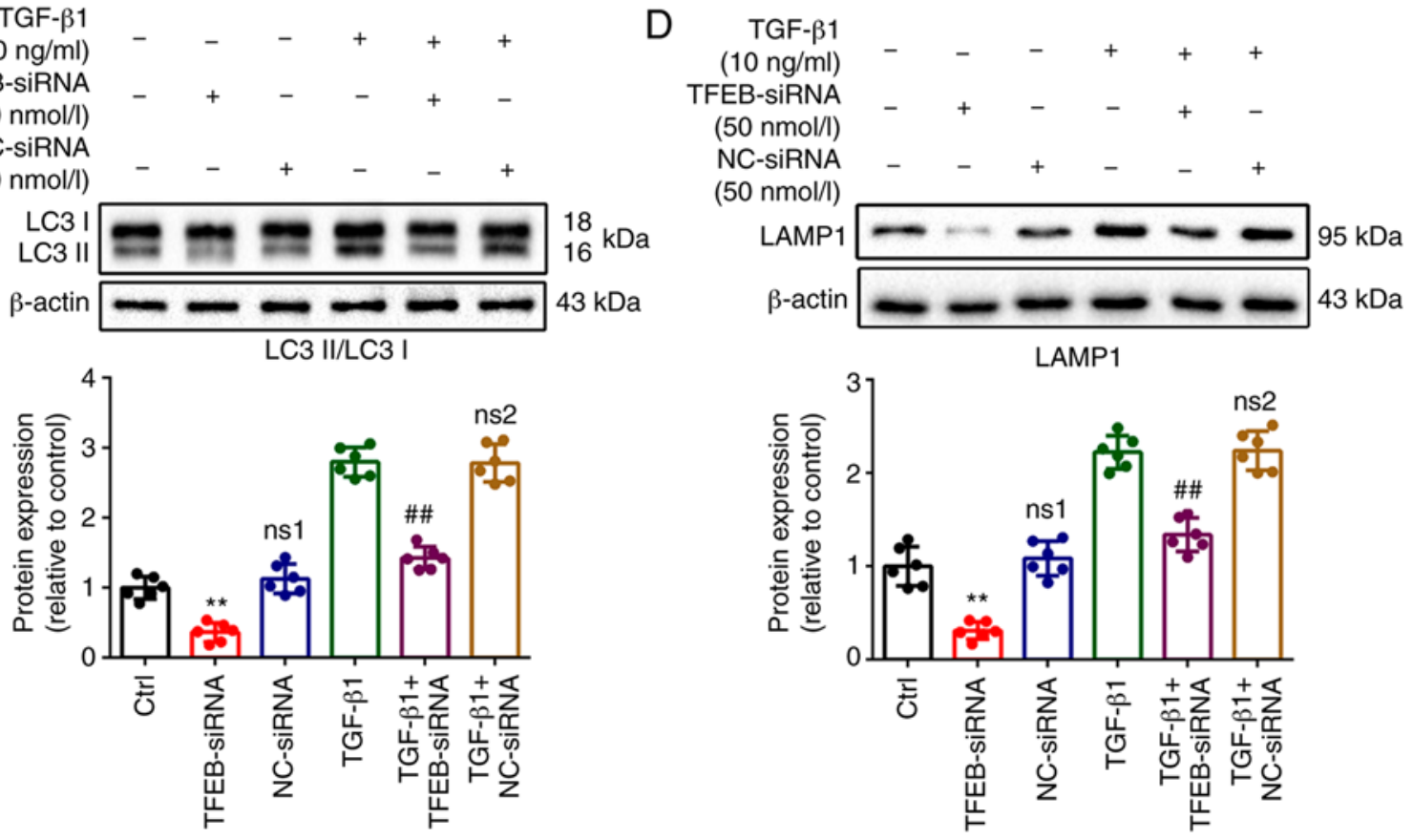

Figure 4. TFEB-siRNA inhibits activation of TFEB and expression of autophagy-associated proteins in fibroblasts treated with or without TGF- $\beta 1$. Fibroblasts were transfected with $50 \mathrm{nmol} / 1$ TFEB-siRNA or NC-siRNA for $48 \mathrm{~h}$ and then treated with or without $10 \mathrm{ng} / \mathrm{ml}$ TGF- $\beta 1$ for $48 \mathrm{~h}$. The expression of TFEB was evaluated by (A) reverse transcription-quantitative PCR and (B) western blotting. The expression of (C) LC3 and (D) LAMP1 was determined by western blotting. $\beta$-actin served as a loading control. Results are presented as the mean $\pm \mathrm{SD}(\mathrm{n}=6)$. ${ }^{*} \mathrm{P}<0.05$ and ${ }^{* * *} \mathrm{P}<0.01$ vs. control group; ${ }^{\# \#} \mathrm{P}<0.01$ vs. TGF- $\beta 1$ treatment group. TGF- $\beta 1$, transforming growth factor- $\beta 1$; TFEB, transcription factor EB; siRNA, small interfering RNA; NC, negative control; LC3, microtubule associated protein 1 light chain 3; LAMP1, lysosome-associated membrane protein 1; ns1, not significant compared with control group; ns2, not significant compared with TGF- $\beta 1$ treatment group.

of pro-COL I $\alpha 1$ in the culture supernatants $(22.07 \pm 3.14$ vs. $11.49 \pm 1.41 ; \mathrm{P}<0.01$; Fig. $7 \mathrm{E} ; 21.86 \pm 3.25$ vs. $11.20 \pm 2.10$; $\mathrm{P}<0.01$; Fig. S3D) compared with the control group. These changes were reversed by TFEB knockdown $[0.29 \pm 0.06$ vs. $0.59 \pm 0.12(\mathrm{P}<0.01 ;$ Fig. $7 \mathrm{C}) ; 0.10 \pm 0.04$ vs. $0.54 \pm 0.08(\mathrm{P}<0.01$; Fig. 7D); $14.54 \pm 2.41$ vs. $22.07 \pm 3.14(\mathrm{P}<0.01$; Fig. $7 \mathrm{E})$; $14.57 \pm 2.22$ vs. $21.86 \pm 3.25(\mathrm{P}<0.01$; Fig. S3D)]. These data suggested that COL I may be secreted via the secretory autophagy pathway during myofibroblast differentiation and proliferation.

\section{Discussion}

Myofibroblasts, which are transformed from activated fibroblasts, can serve as the source of de novo synthesis and secretion of collagen proteins that connect with the collagen 

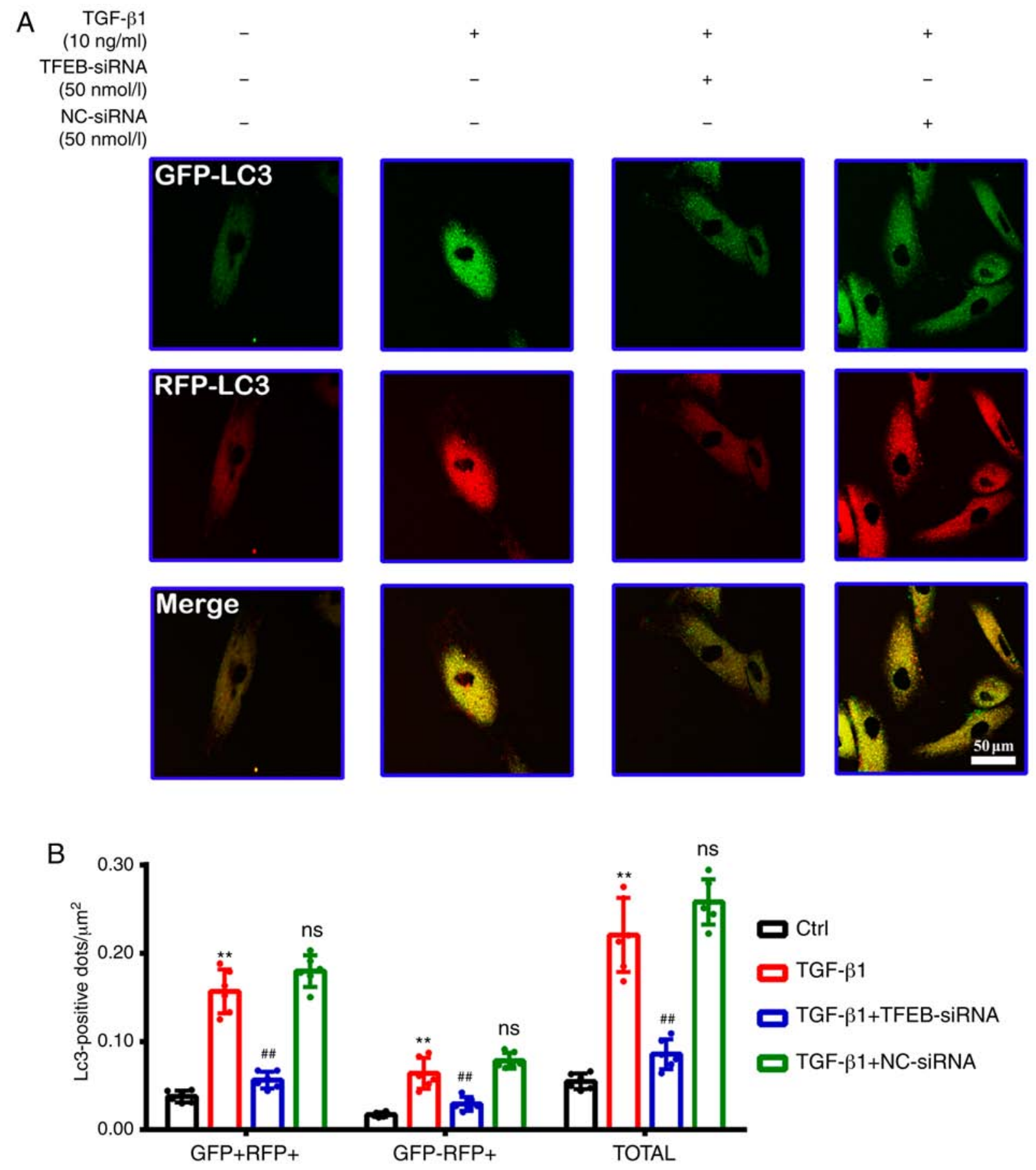

Figure 5. TFEB-siRNA inhibits TGF- $\beta 1$-induced enhancement of autophagic flux. Fibroblasts were transfected with $50 \mathrm{nmol} / 1 \mathrm{TFEB}-\mathrm{siRNA}$ or NC-siRNA for $48 \mathrm{~h}$ and then treated with $10 \mathrm{ng} / \mathrm{ml}$ TGF- $\beta 1$ for $48 \mathrm{~h}$. After TGF- $\beta 1$ treatment for $24 \mathrm{~h}$, cells were treated with mRFP-GFP-LC 3 expressing plasmid for another $24 \mathrm{~h}$. (A and B) Autophagic flux quantified by determining the number of autophagosomes (yellow puncta) and autolysosomes (red puncta) per cell per $\mu \mathrm{m}^{2}$ as illustrated in fluorescent images (scale bar, $50 \mu \mathrm{m}$ ). GFP+RFP+ represents yellow puncta; GFP-RFP+ represents red puncta; total represents yellow+, red puncta. Results are presented as the mean $\pm \mathrm{SD}(\mathrm{n}=6) .{ }^{* *} \mathrm{P}<0.01$ vs. control group; ${ }^{\# \#} \mathrm{P}<0.01$ vs. TGF- $\beta 1$ treatment group. TGF- $\beta 1$, transforming growth factor- $\beta 1$; TFEB, transcription factor EB; siRNA, small interfering RNA; NC, negative control; ns, not significant compared with TGF- $\beta 1$ treatment group.

proteins on the edge of wounded tissues, and promote the edges to shrink together, thus playing a key role in the early stage of the wound-healing process (28). During the remodeling phase of wound-healing, myofibroblasts undergo a shift from proliferation to apoptosis in order to clear the wound site (29). However, under fibrotic conditions, myofibroblasts are continuously activated, and remain as the fibrotic phenotype, which are resistant to apoptosis. At present, the underlying molecular mechanisms during this process have not been fully elucidated. Autophagy has been demonstrated to be closely associated with the pathological process of numerous fibrotic diseases. The present study provided insight into how TGF- $\beta 1$-induced autophagy leads to less misfolded collagen in dermal fibroblasts through autophagic degradation and autophagy-dependent secretion, along with reduced ER stress and prevention of cell apoptosis.

It is commonly known that TGF- $\beta 1$ plays a key modulatory role in the proliferation of fibroblasts and the accumulation 

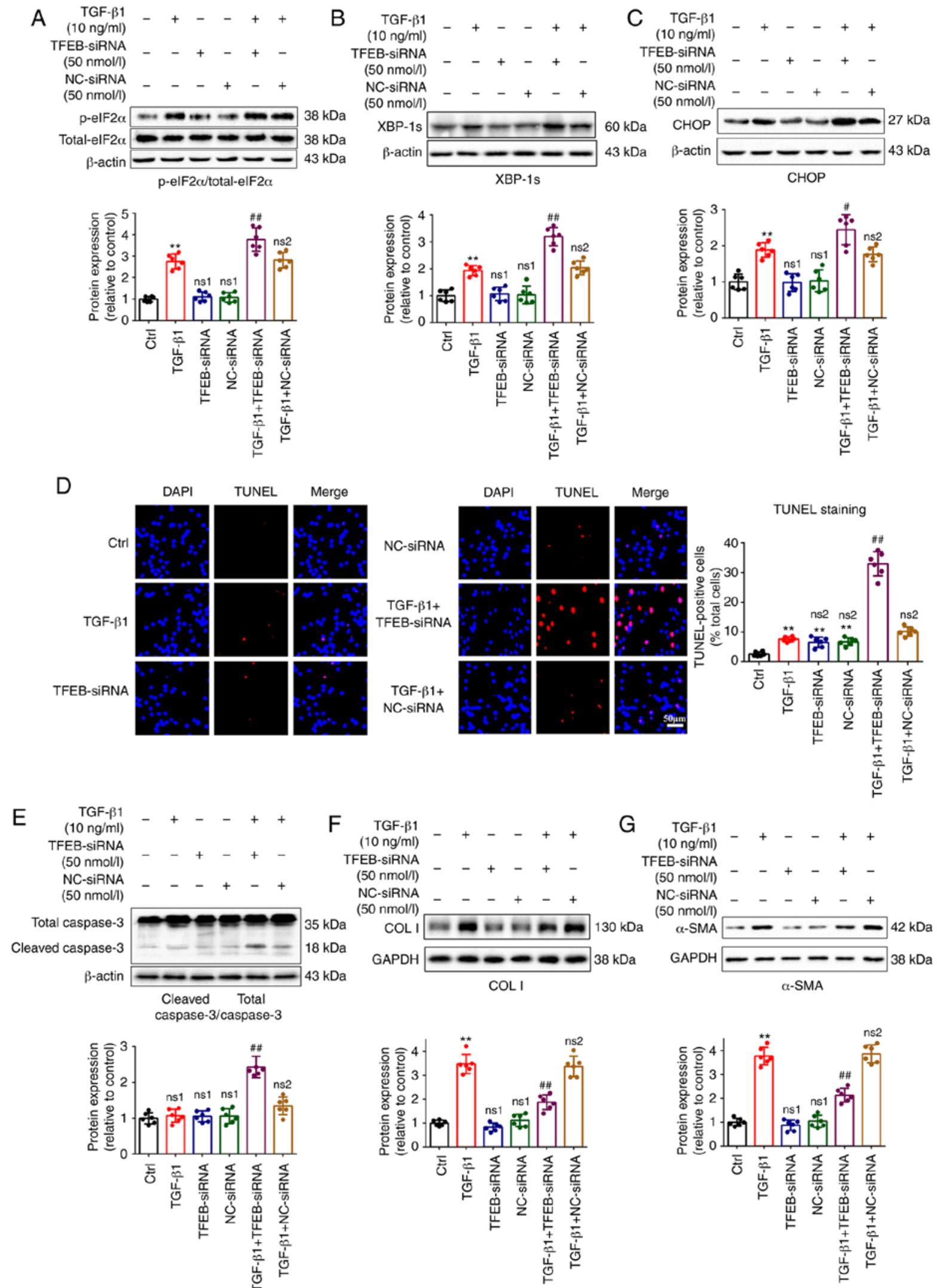

Figure 6. TFEB-siRNA enhances TGF- $\beta 1$-induced ER stress and apoptosis, while it reduces the phenotypic transformation and collagen synthesis in fibroblasts. Fibroblasts were transfected with $50 \mathrm{nmol} / 1 \mathrm{TFEB}$-siRNA or NC-siRNA for $48 \mathrm{~h}$ and then treated with or without $10 \mathrm{ng} / \mathrm{ml} \mathrm{TGF}-\beta 1 \mathrm{for} 48 \mathrm{~h}$. The expression of (A) p-eIF2 $\alpha /$ total-eIF2 $\alpha$, (B) XBP-1s, (C) CHOP, (E) cleaved caspase 3/total caspase 3, (F) COL I and (G) $\alpha$-SMA in fibroblasts was determined by western blotting. GAPDH or $\beta$-actin served as a loading control. (D) Apoptotic fibroblasts were analyzed by TUNEL staining (scale bar, $50 \mu \mathrm{m}$ ). Results are presented as the mean $\pm \mathrm{SD}(\mathrm{n}=6) .{ }^{* *} \mathrm{P}<0.01$ vs. control group; ${ }^{\#} \mathrm{P}<0.05$ and ${ }^{\# \#} \mathrm{P}<0.01$ vs. TGF- $\beta 1$ treatment group. TGF- $\beta 1$, transforming growth factor- $\beta 1$; TFEB, transcription factor EB; siRNA, small interfering RNA; NC, negative control; ER, endoplasmic reticulum; p-, phosphorylated; eIF2 $\alpha, \alpha$ subunit of eukaryotic initiation factor 2; CHOP, C/EBP-homologous protein caspase 3; XBP-1s, spliced X-box binding protein 1; caspase 3, cysteinyl aspartate specific proteinase 3; $\alpha$-SMA, $\alpha$ smooth muscle actin; COL I, collagen I; TUNEL, terminal deoxynucleotidyl transferase-mediated biotinylated UTP nick-end labeling; ns1, not significant compared with control group; ns2, not significant compared with TGF- $\beta 1$ treatment group. 

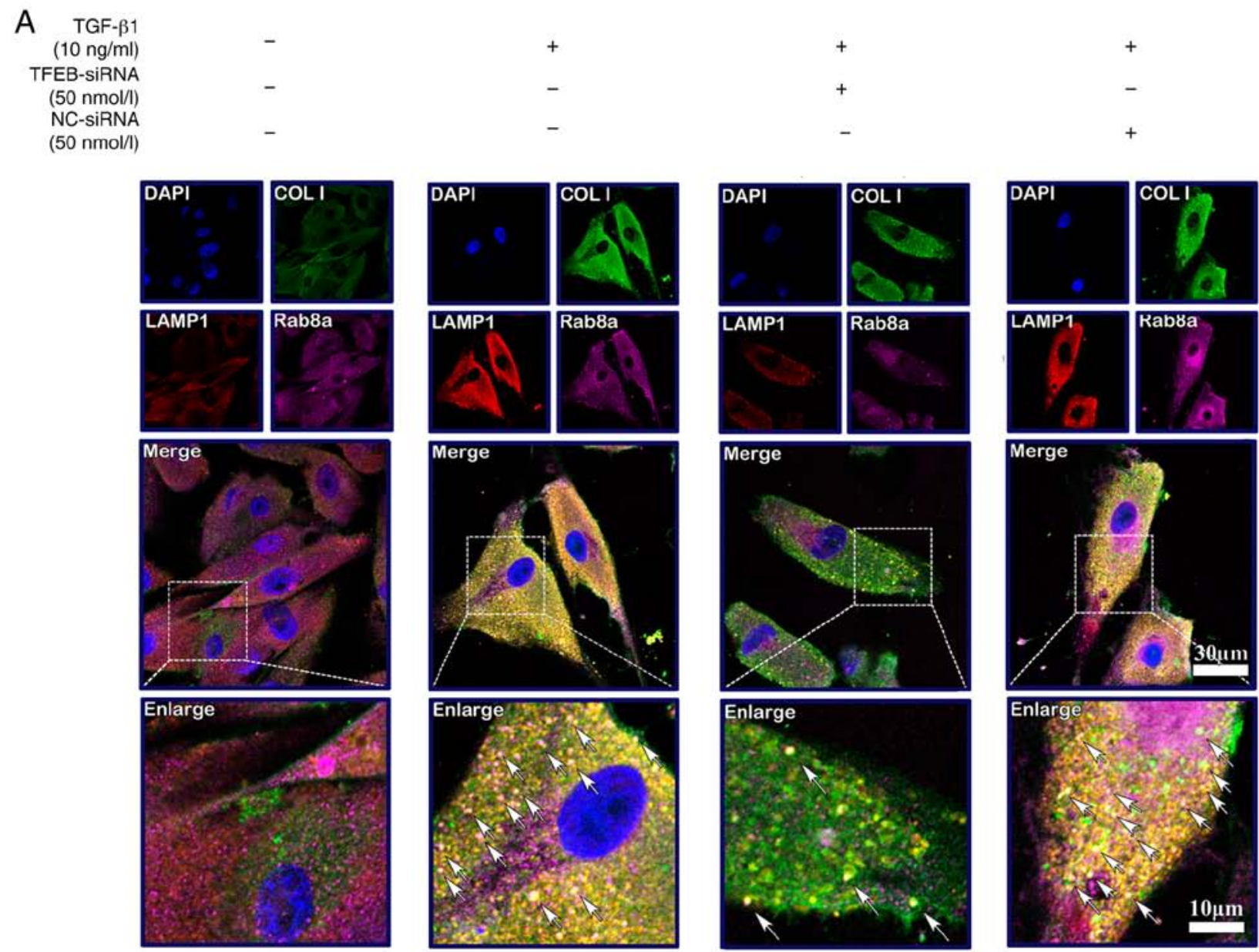

B
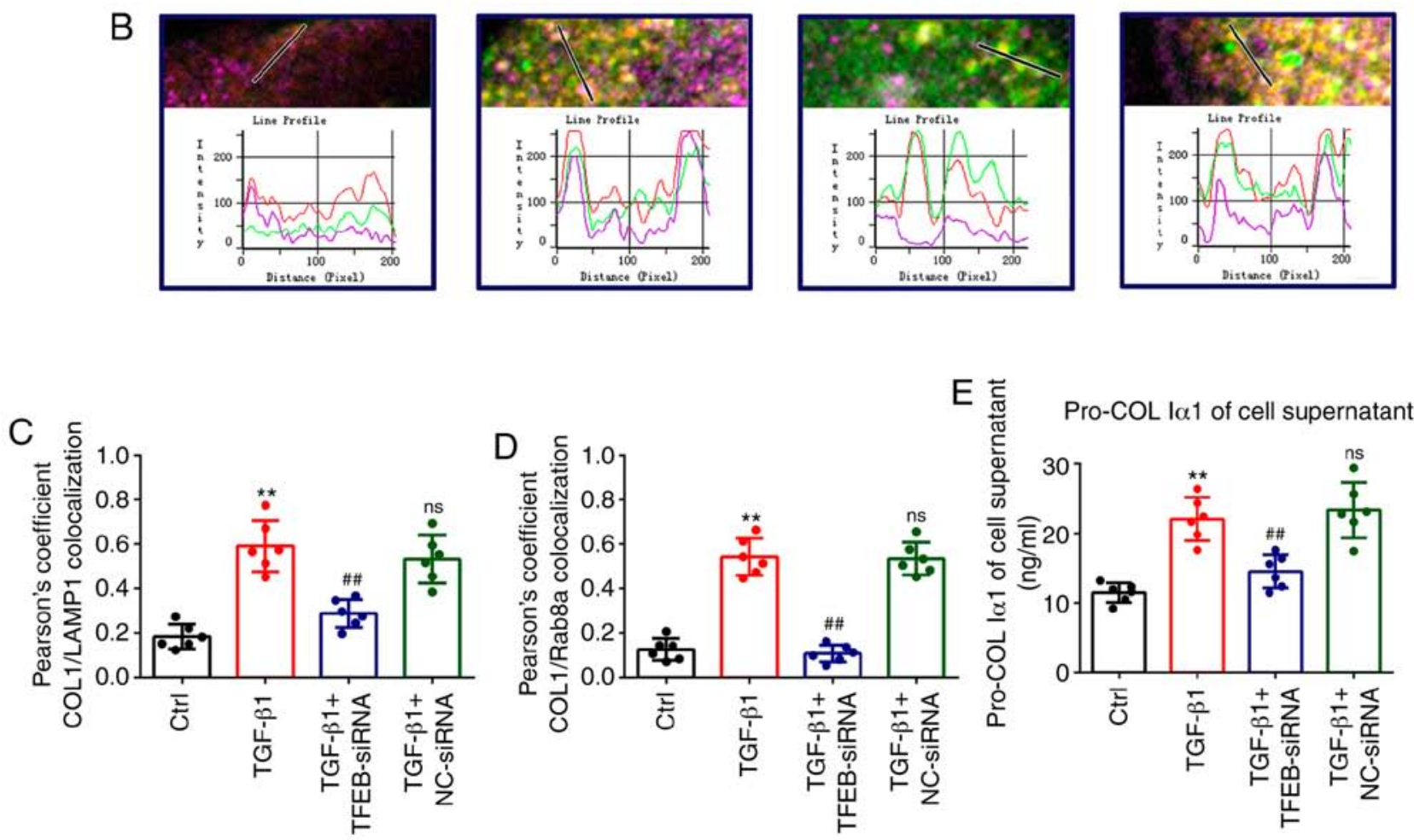

Figure 7. TGF- $\beta 1$-induced COL I secretion from fibroblasts is associated with an autophagy-based pathway. Fibroblasts were treated with $50 \mathrm{nmol} / 1$ TFEB-siRNA or NC-siRNA for $48 \mathrm{~h}$ and then with $10 \mathrm{ng} / \mathrm{ml}$ TGF- $\beta 1$ for $48 \mathrm{~h}$. (A) Fluorescence for colocalization of Rab8a with LAMP1 and COL I (scale bars, 10 or $30 \mu \mathrm{m}$ ). (B) Line tracing analysis of fluorescence signal intensity. (C) Pearson's colocalization coefficient for COL I and LAMP1. (D) Pearson's colocalization coefficient for COL I and Rab8a. (E) Pro-COL I $\alpha 1$ secretion in the supernatant of fibroblasts was assessed by enzyme-linked immunosorbent assay. Results are presented as the mean $\pm \mathrm{SD}(\mathrm{n}=6) .{ }^{* *} \mathrm{P}<0.01$ vs. control group; ${ }^{\# \#} \mathrm{P}<0.01$ vs. TGF- $\beta 1$ treatment group. TGF- $\beta 1$, transforming growth factor- $\beta 1$; TFEB, transcription factor EB; siRNA, small interfering RNA; NC, negative control; COL I, collagen I; Rab8a, Ras-related protein Rab-8A; LAMP1, lysosome-associated membrane protein 1 ; ns, not significant compared with TGF- $\beta 1$ treatment group. 
of ECM via the Smad signaling pathway (30). In the present study, western blotting and ELISA results also confirmed that $10 \mathrm{ng} / \mathrm{ml}$ TGF- $\beta 1$ effectively increased collagen content, not only in fibroblasts, but also in culture supernatants. Synthesized and folded in the ER, collagen is composed of three pro-chains that form a triple helix (31). Despite its relatively simple structure, the folding of collagen is very difficult due to its thermodynamic instability, and relies on multiple chaperones, such as collagen prolyl 4-hydroxylase, GRP78, protein disulfide-isomerase and heat shock protein 47, which stabilize native structures and prevent aggregation of unfolded chains (27,32-35). Unfolded or misfolded proteins are harmful and must be folded into the appropriate conformation to perform their cellular functions. TGF- $\beta 1$ promotes protein synthesis and increases the demand for the protein-folding capacity of ER, which disturbs ER homeostasis, resulting in increased ER stress and activation of a network of signaling pathways, known as the unfolded protein response (UPR), which is mediated through three sensors: PERK, IRE1 $\alpha$ and ATF6 (36). These proteins dissociate from GRP78 and then activate downstream signaling pathways, which suppress protein translation, enhance protein folding and promote unfolded or misfolded protein degradation (37). The positive effects of TGF- $\beta 1$ on ER stress were confirmed in the current study by the upregulated expression of these ER stress markers. Activation of UPR signaling is known to induce the ER-associated degradation (ERAD) system, which mediates the degradation of misfolded collagen molecules from the ER (38). However, the ERAD pathway can only degrade collagen monomers, and cannot degrade collagen trimmers once they are formed (39). The persistence of uncompensated ER stress eventually induces apoptosis. Thus, there must be other underlying mechanisms that contribute to the reduction of ER stress in the context of fibrosis.

Autophagy is an essential lysosome-dependent degradation pathway that is involved in the breakdown of cellular organelles and protein complexes too large for proteasomal degradation (40). Similar to UPR, autophagy is also associated with both cell survival and death (41). The present study observed that the expression levels of autophagy-related proteins and the key regulator of autophagy, TFEB, were upregulated, which was consistent with the changes of ER stress marker proteins in fibroblasts treated with TGF- $\beta 1$. It was shown in this study that the ER stress inhibitor TUDCA was also able to downregulate autophagy, indicating that autophagy may be upregulated by ER stress in differentiated fibroblasts.

Therefore, autophagy was further downregulated through knockdown of TFEB to investigate whether autophagy is the mechanism of the reduction of ER stress and promotion of cell survival by autophagy under fibrotic conditions. Under normal conditions, TFEB is phosphorylated and localized in the cytoplasm, and does not exhibit any function. Under the circumstances of starvation or oxidation stimulation, TFEB is dephosphorylated, translocated to the nucleus, and activates the transcription of genes related to autophagy and lysosome biogenesis (42). TFEB plays a pivotal role in regulating the process of autophagy $(23,43)$. As expected, in the present study knockdown of TFEB enhanced the apoptosis of fibroblasts by activating the CHOP pathway, as well as reducing the phenotypic transformation of fibroblasts and the synthesis and secretion of collagen. CHOP plays an important role in ER stress-induced apoptosis (44). The transcription of CHOP is activated via the PERK/eIF2a/ATF4 and IRE1 $\alpha / \mathrm{XBP}-1 \mathrm{~s}$ pathways, which transmits to the mitochondria and finally leads to caspase 3 activation (45). Notably, the downregulation of autophagy-mediated apoptosis only occurred in activated fibroblasts, but not in quiescent fibroblasts in the present study. This finding suggested that knockdown of TFEB aggravated the pre-existing ER stress response, converting adaptive signaling to apoptotic signaling. Collectively, these results confirm that TFEB-mediated autophagy could maintain the survival and function of fibroblasts by eliminating misfolded/unfolded proteins. However, given that the role of autophagy in the pathogenesis of diseases is multifaceted and complex, whether upregulated autophagy by overexpression of TFEB could promote fibroblast proliferation or lead to further autophagic death needs to be further elucidated in future research.

In general, secretory proteins are released from the ER to the Golgi apparatus and subsequently into the extracellular space, and this process is mediated by COPII-coated vesicles (27). However, fibroblasts do not contain any evidently large COPII structures, and collagen molecules are too large to be incorporated into the conventional $80-\mathrm{nm}$ COPII-coated vesicles (27). Thus, an alternative pathway of trafficking is required for the export of collagen from the ER in the absence of large carriers, particularly when handling unfolded and/or misfolded procollagen.

ER exit sites are physically and functionally associated with autophagosome formation (46). While autophagy was initially defined as a cellular process that results in isolation of cytosolic cargoes and their degradation in lysosomes, it has also been recognized as a contributor to autophagy-dependent secretion ('secretory autophagy'), which bypasses the ER-Golgi complex and also promotes toxic protein clearance and cell-cell signaling communications (47-50). Secretory autophagy was initially identified in studies that investigated unconventional protein secretion, for example how proteins that are unable to enter the ER due to lack of signal peptides are released to the extracellular space (51). However, it has been revealed that autophagy is also involved in the regulation of conventional secretion, with different roles in different cell types $(52,53)$. Secretory autophagy is a tightly regulated process, but its underlying molecular machinery is far from elucidated. Evidence has indicated that certain factors are necessary for secretory autophagy, among which the small GTPase Rab8a is considered to be a useful available marker as a regulator of polarized sorting of proteins to the plasma membrane (54). The present study demonstrated that Rab8a colocalized with COL I and LAMP1 in fibroblasts following exposure to TGF- $\beta 1$. Autophagy inhibition by knockdown of TFEB significantly reduced colocalization of COL I with Rab8a and LAMP1, and also decreased the secretion level of pro-COL I $\alpha 1$ in the cell culture supernatant. These data indicated that apart from autophagic degradation, COL I in the autolysosome can also be released to the extracellular space via autophagy-dependent secretion machinery. Therefore, autophagy-dependent secretion is also an important cellular clearance mechanism for the maintenance of cell homeostasis under fibrotic conditions. In 
addition, collagen fibrils can only be formed after procollagen is cross-linked following cleavage of terminal pro-peptides by procollagen $\mathrm{N}$ - and $\mathrm{C}$-proteinases (55). Therefore, it can be speculated that misfolded or unfolded COL I secreted via autolysosome to the extracellular environment in the process of secretory autophagy may be a cause of the faulty assembly and irregular arrangement of collagen fibers in HTS.

In conclusion, the present study demonstrated that TFEB-mediated autophagy reduced ER stress, decreased cell apoptosis and maintained the activated phenotype of fibroblasts, not only through degradation of misfolded or unfolded proteins, but also via release of COL I from the autolysosome to the extracellular environment via autophagy-dependent secretion machinery. The results may provide an improved understanding of the roles of autophagy in the formation of HTS. The inhibition of autophagy and lysosomal biogenesis may serve as a novel direction for the development of treatment strategies for HTS.

\section{Acknowledgements}

Not applicable.

\section{Funding}

This work was supported by Hubei Natural Science Foundation (grant no. 2018CKB904).

\section{Availability of data and materials}

The datasets used and/or analyzed during this study are available from the corresponding author upon reasonable request.

\section{Authors' contributions}

LZ and ZL designed and conducted the experiments. LG and GY participated in designing the experiments and proofreading the article. SC assisted in data collection and manuscript preparation. JQ, QL, SW and WZ participated in performing the experiments. DC performed data analysis. All authors read and approved the final manuscript.

\section{Ethics approval and consent to participate}

This research was approved by the Medical Ethics Committee of Zhongnan Hospital of Wuhan University (Wuhan, China; approval no. 2019006) and complied with the ethical standards of the Declaration of Helsinki as well as the relevant national and international guidelines. Each patient signed an informed consent for the use of their abandoned skin tissue in the research.

\section{Patient consent for publication}

Written informed consent was obtained from each patient.

\section{Competing interests}

The authors declare that they have no competing interests.

\section{References}

1. Benzaquen M, Collet-Villette AM and Delaporte E: Combined treatment of hypertrophic and keloid scars with intralesional injection of corticosteroids and laser-assisted corticosteroid delivery. Dermatol Ther 32: e13126, 2019.

2. Del Toro D, Dedhia R and Tollefson TT: Advances in scar management: Prevention and management of hypertrophic scars and keloids. Curr Opin Otolaryngol Head Neck Surg 24: 322-329, 2016.

3. Zhang J, Li Y, Bai X, Li Y, Shi J and Hu D: Recent advances in hypertrophic scar. Histol Histopathol 33: 27-39, 2018.

4. Gras C, Ratuszny D, Hadamitzky C, Zhang H, Blasczyk R and Figueire do C: miR-145 contributes to hypertrophic scarring of the skin by inducing myofibroblast activity. Mol Med 21: 296-304, 2015.

5. Darby IA, Zakuan N, Billet F and Desmoulière A: The myofibroblast, a key cell in normal and pathological tissue repair. Cell Mol Life Sci 73: 1145-1157, 2016.

6. Hinz B: The role of myofibroblasts in wound healing. Curr Res Transl Med 64: 171-177, 2016.

7. Pakyari M, Farrokhi A, Maharlooei MK and Ghahary A: Critical role of transforming growth factor beta in different phases of wound healing. Adv Wound Care (New Rochelle) 2: 215-224, 2013.

8. Zhang Y, Cheng C, Wang S, Xu M, Zhang D and Zeng W: Knockdown of FOXM1 inhibits activation of keloid fibroblasts and extracellular matrix production via inhibition of TGF- $31 /$ Smad pathway. Life Sci 232: 116637, 2019.

9. Alizadeh J, Glogowska A, Thliveris J, Kalantari F, Shojaei S, Hombach-Klonisch S, Klonisch T and Ghavami S: Autophagy modulates transforming growth factor beta 1 induced epithelial to mesenchymal transition in non-small cell lung cancer cells. Biochim Biophys Acta Mol Cell Res 1865: 749-768, 2018.

10. Liang C, Xu J, Meng Q, Zhang B, Liu J, Hua J, Zhang Y, Shi S and Yu X: TGFB1-induced autophagy affects the pattern of pancreatic cancer progression in distinct ways depending on SMAD4 status. Autophagy 16: 486-500, 2020.

11. Cuomo F, Altucci L and Cobellis G: Autophagy function and dysfunction: Potential drugs as anti-cancer therapy. Cancers (Basel) 11: 1465, 2019.

12. Fitzwalter BE and Thorburn A: Recent insights into cell death and autophagy. FEBS J 282: 4279-4288, 2015.

13. Lu C, Yang Y, Zhu Y, Lv S and Zhang J: An intervention target for myocardial fibrosis: Autophagy. Biomed Res Int 2018: 6215916, 2018.

14. Maiuri L and Kroemer G: Autophagy delays progression of the two most frequent human monogenetic lethal diseases: Cystic fibrosis and Wilson disease. Aging (Albany NY) 10: 3657-3661, 2018.

15. Tseng YJ, Dong L, Liu YF, Xu N, Ma W, Weng SQ, Janssen HLA and $\mathrm{Wu}$ SD: Role of autophagy in chronic liver inflammation and fibrosis. Curr Protein Pept Sci 20: 817-822, 2019.

16. Zhao XC, Livingston MJ, Liang XL and Dong Z: Cell apoptosis and autophagy in renal fibrosis. Adv Exp Med Biol 1165: 557-584, 2019.

17. Lodder J, Denaës T, Chobert MN, Wan J, El-Benna J, Pawlotsky JM, Lotersztajn S and Teixeira-Clerc F: Macrophage autophagy protects against liver fibrosis in mice. Autophagy 11: 1280-1292, 2015

18. Cabrera S, Maciel M, Herrera I, Nava T, Vergara F, Gaxiola M, López-Otín C, Selman M and Pardo A: Essential role for the ATG4B protease and autophagy in bleomycin-induced pulmonary fibrosis. Autophagy 11: 670-684, 2015.

19. Takagaki Y, Lee SM, Dongqing Z, Kitada M, Kanasaki K and Koya D: Endothelial autophagy deficiency induces IL6-dependent endothelial mesenchymal transition and organ fibrosis. Autophagy 16: 1905-1914, 2020.

20. Frangou E, Chrysanthopoulou A, Mitsios A, Kambas K, Arelaki S, Angelidou I, Arampatzioglou A, Gakiopoulou H, Bertsias GK, Verginis P, et al: REDD1/autophagy pathway promotes thromboinflammation and fibrosis in human systemic lupus erythematosus (SLE) through NETs decorated with tissue factor (TF) and interleukin-17A (IL-17A). Ann Rheum Dis 78: 238-248, 2019.

21. San-Miguel B, Crespo I, Sánchez DI, González-Fernández B, Ortiz de Urbina JJ, Tuñón MJ and González-Gallego J: Melatonin inhibits autophagy and endoplasmic reticulum stress in mice with carbon tetrachloride-induced fibrosis. J Pineal Res 59: 151-162, 2015. 
22. Livingston MJ, Ding HF, Huang S, Hill JA, Yin XM and Dong Z: Persistent activation of autophagy in kidney tubular cells promotes renal interstitial fibrosis during unilateral ureteral obstruction. Autophagy 12: 976-998, 2016.

23. Settembre C, Di Malta C, Polito VA, Garcia Arencibia M Vetrini F, Erdin S, Erdin SU, Huynh T, Medina D, Colella P, et al: TFEB links autophagy to lysosomal biogenesis. Science 332 1429-1433, 2011.

24. DuF,Zhu L,QianZM,Wu XM, Yung WHand Ke Y:Hyperthermic preconditioning protects astrocytes from ischemia/reperfusion injury by up-regulation of HIF-1 alpha expression and binding activity. Biochim Biophys Acta 1802: 1048-1053, 2010.

25. Livak KJ and Schmittgen TD: Analysis of relative gene expression data using real-time quantitative PCR and the 2(-Delta Delta C(T)) method. Methods 25: 402-408, 2001.

26. Cybulsky AV: The intersecting roles of endoplasmic reticulum stress, ubiquitin-proteasome system, and autophagy in the pathogenesis of proteinuric kidney disease. Kidney Int 84: 25-33, 2013.

27. McCaughey J and Stephens DJ: ER-to-golgi transport: A sizeable problem. Trends Cell Biol 29: 940-953, 2019.

28. Schnieder J, Mamazhakypov A, Birnhuber A, Wilhelm J, Kwapiszewska G, Ruppert C, Markart P, Wujak L, Rubio K, Barreto G, et al: Loss of LRP1 promotes acquisition of contractile-myofibroblast phenotype and release of active TGF- $\beta 1$ from ECM stores. Matrix Biol 88: 69-88, 2020.

29. Dolivo DM, Larson SA and Dominko T: Fibroblast growth factor 2 as an antifibrotic: Antagonism of myofibroblast differentiation and suppression of pro-fibrotic gene expression. Cytokine Growth Factor Rev 38: 49-58, 2017.

30. Meng XM, Nikolic-Paterson DJ and Lan HY: TGF- $\beta$ : The master regulator of fibrosis. Nat Rev Nephrol 12: 325-338, 2016.

31. Kirkness MW, Lehmann K and Forde NR: Mechanics and structural stability of the collagen triple helix. Curr Opin Chem Biol 53: 98-105, 2019

32. Saito K, Maeda M and Katada T: Regulation of the Sarl GTPase cycle is necessary for large cargo secretion from the endoplasmic reticulum. Front Cell Dev Biol 5: 75, 2017.

33. Gjaltema RA and Bank RA: Molecular insights into prolyl and lysyl hydroxylation of fibrillar collagens in health and disease. Crit Rev Biochem Mol Biol 52: 74-95, 2017.

34. Sorushanova A, Delgado LM, Wu Z, Shologu N, Kshirsagar A Raghunath R, Mullen AM, Bayon Y, Pandit A, Raghunath M and Zeugolis DI: The collagen suprafamily: From biosynthesis to advanced biomaterial development. Adv Mater 31: e1801651, 2019.

35. Ishikawa Y and Bächinger HP: A molecular ensemble in the rER for procollagen maturation. Biochim Biophys Acta 1833: 2479-2491, 2013

36. Hetz C, Zhang K and Kaufman RJ: Mechanisms, regulation and functions of the unfolded protein response. Nat Rev Mol Cell Biol 21: 421-438, 2020.

37. Shu S, Zhu J, Liu Z, Tang C, Cai J and Dong Z: Endoplasmic reticulum stress is activated in post-ischemic kidneys to promote chronic kidney disease. EBioMedicine 37: 269-280, 2018.

38. Kropski JA and Blackwell TS: Endoplasmic reticulum stress in the pathogenesis of fibrotic disease. J Clin Invest 128: 64-73, 2018.

39. Ishida $Y$ and Nagata K: Autophagy eliminates a specific species of misfolded procollagen and plays a protective role in cell survival against ER stress. Autophagy 5: 1217-1219, 2009.
40. Nabar NR, Shi CS and Kehrl JH: Signaling by the toll-like receptors induces autophagy through modification of beclin 1: Molecular Mechanism. In: Immunology. Hayat MA (ed). Academic Press, London, pp75-84, 2018.

41. Swart C, Du Toit A and Loos B: Autophagy and the invisible line between life and death. Eur J Cell Biol 95: 598-610, 2016.

42. Füllgrabe J, Klionsky DJ and Joseph B: The return of the nucleus: Transcriptional and epigenetic control of autophagy. Nat Rev Mol Cell Biol 15: 65-74, 2014.

43. Napolitano G and Ballabio A: TFEB at a glance. J Cell Sci 129 2475-2481, 2016

44. Kandel-Kfir M, Almog T, Shaish A, Shlomai G, Anafi L, Avivi C, Barshack I, Grosskopf I, Harats D and Kamari Y: Interleukin-1a deficiency attenuates endoplasmic reticulum stress-induced liver damage and CHOP expression in mice. J Hepatol 63: 926-933, 2015.

45. Oyadomari S and Mori M: Roles of CHOP/GADD153 in endoplasmic reticulum stress. Cell Death Differ 11: 381-389, 2004

46. Sanchez-Wandelmer J, Ktistakis NT and Reggiori F: ERES: Sites for autophagosome biogenesis and maturation? J Cell Sci 128: 185-192, 2015

47. Ponpuak M, Mandell MA, Kimura T, Chauhan S, Cleyrat C and Deretic V: Secretory autophagy. Curr Opin Cell Biol 35: 106-116, 2015.

48. Kimura T, Jia J, Claude-Taupin A, Kumar S, Choi SW, Gu Y, Mudd M, Dupont N, Jiang S, Peters R, et al: Cellular and molecular mechanism for secretory autophagy. Autophagy 13: 1084-1085, 2017.

49. Bel S and Hooper LV: Secretory autophagy of lysozyme in Paneth cells. Autophagy 14: 719-721, 2018.

50. New J, Arnold L, Ananth M, Alvi S, Thornton M, Werner L, Tawfik O, Dai H, Shnayder Y, Kakarala K, et al: Secretory autophagy in cancer-associated fibroblasts promotes head and neck cancer progression and offers a novel therapeutic target. Cancer Res 77: 6679-6691, 2017.

51. Rabouille C: Pathways of unconventional protein secretion. Trends Cell Biol 27: 230-240, 2017.

52. Gonzalez CD, Resnik R and Vaccaro MI: Secretory autophagy and its relevance in metabolic and degenerative disease. Front Endocrinol (Lausanne) 11: 266, 2020.

53. Cavalli G and Cenci S: Autophagy and protein secretion. J Mol Biol 432: 2525-2545, 2020.

54. Ejlerskov P, Rasmussen I, Nielsen TT, Bergström AL, Tohyama Y, Jensen PH and Vilhardt F: Tubulin polymerization-promoting protein (TPPP/p25 $\alpha$ ) promotes unconventional secretion of $\alpha$-synuclein through exophagy by impairing autophagosome-lysosome fusion. J Biol Chem 288: 17313-17335, 2013.

55. Khoshnoodi J, Cartailler JP, Alvares K, Veis A and Hudson BG: Molecular recognition in the assembly of collagens: Terminal noncollagenous domains are key recognition modules in the formation of triple helical protomers. J Biol Chem 281: 38117-38121, 2006. 